\title{
The Effects of Surface Longwave Spectral Emissivity on Atmospheric Circulation and Convection over the Sahara and Sahel
}

\author{
Yi-Hsuan Chen, Xianglei Huang, Xiuhong Chen, and Mark Flanner \\ Department of Climate and Space Sciences and Engineering, University of Michigan, Ann Arbor, Michigan
}

(Manuscript received 19 September 2018, in final form 19 March 2019)

\begin{abstract}
This study quantifies the impact of the inclusion of realistic surface spectral emissivity in the Sahara and Sahel on the simulated local climate and beyond. The surface emissivity in these regions can be as low as $0.6-0.7$ over the infrared window band while close to unity in other spectral bands, but such spectral dependence has been ignored in current climate models. Realistic surface spectral emissivities over the Sahara and Sahel are incorporated into the Community Earth System Model (CESM) version 1.1.1, while treatments of surface emissivity for the rest of the globe remain unchanged. Both the modified and standard CESM are then forced with prescribed climatological SSTs and fixed present-day forcings for 35-yr simulations. The outputs from the last 30 years are analyzed. Compared to the standard CESM, the modified CESM has warmer surface air temperature, as well as a warmer and wetter planetary boundary layer over the Sahara and Sahel. The modified CESM thus favors more convection in these regions and has more convective rainfall, especially in the Sahara. The moisture convergence induced by such inclusion of surface spectral emissivity also contributes to the differences in simulated precipitation in the Sahel and the region south to it. Compared to observations, inclusion of surface spectral emissivity reduces surface temperature biases in the Sahara and precipitation biases in the Gulf of Guinea but exacerbates the wet biases in the Sahara. Such realistic representation of surface spectral emissivity can help unmask other factors contributing to regional biases in the original CESM.
\end{abstract}

\section{Introduction}

Africa is the world's second most populous continent and one of the most vulnerable continents with regard to climate change. The Fifth Assessment Report of the Intergovernmental Panel on Climate Change (IPCC AR5) suggests that by the end of the twenty-first century, the mean annual surface temperature of Africa is likely to rise over $2^{\circ} \mathrm{C}$ and precipitation patterns are likely to change too (IPCC 2013; Sylla et al. 2016; Monerie et al. 2017). These changes can have profound socioeconomic impacts, especially for the Sahara and Sahel. In the late twentieth century a sustained Sahel drought severely affected ecosystem services, in the form of declines in forest area and food production (Epule et al. 2014). In terms of future precipitation changes in the Sahara and Sahel, the magnitude and even the sign of these changes remain uncertain (Druyan 2011; Sylla et al. 2016; Monerie et al. 2017).

The climate research community has invested considerable efforts in the last two decades to understand

\footnotetext{
Corresponding author: Xianglei Huang, xianglei@umich.edu
}

the physical mechanisms that can affect climate variations in the Sahara and Sahel and the surrounding regions. Previous studies suggest that a number of factors can affect the weather and climate in the Sahara and Sahel, such as decadal to multidecadal variability of sea surface temperatures in different ocean basins (Giannini et al. 2003; Mohino et al. 2011; Fontaine et al. 2011; Rodríguez-Fonseca et al. 2015), aerosol and its indirect effects on clouds (Rotstayn and Lohmann 2002; Huang et al. 2019), increases of greenhouse gases (Held et al. 2005; Biasutti 2013, and references therein), Arctic sea ice variability (Smith et al. 2017; Monerie et al. 2019), and surface type changes (Charney et al. 1977). The first and second West African Monsoon Modeling and Evaluation Project Experiment (WAMME I and WAMME II; Xue et al. 2010; Xue et al. 2016) used multimodel experiments to assess the contributions of different factors to the climatology of West African monsoon as well as the Sahel drought. The WAMME II ensemble model results demonstrated that SST forcing is a major contributor to the Sahel drought, but the impact of land use and land cover change on the Sahel drought is also of first-order magnitude. As shown by Charney et al. (1977) and other 
(a)

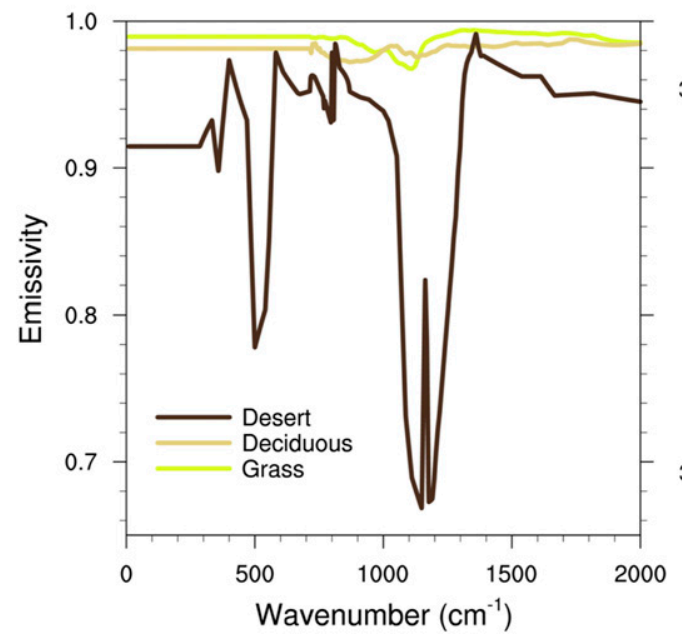

(b)

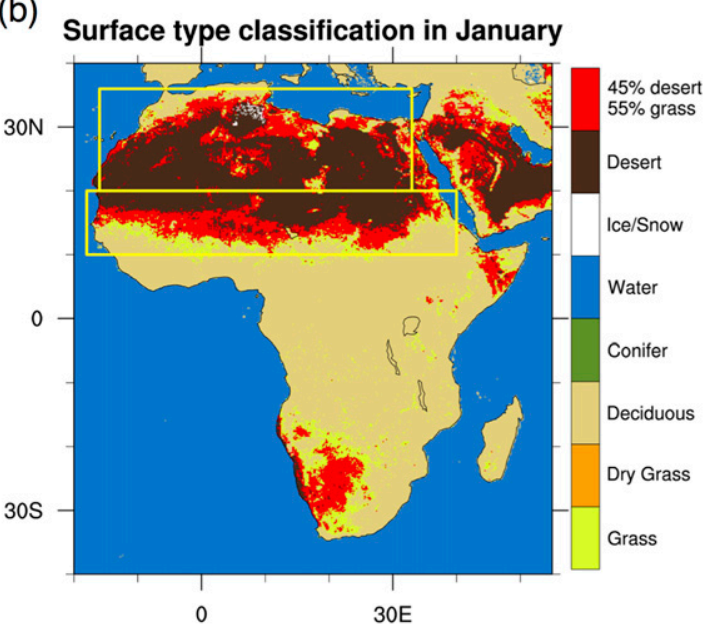

FIG. 1. (a) The LW spectral emissivity of desert (black), deciduous forest (light brown), and grass (light green) from 10 to $2000 \mathrm{~cm}^{-1}$ with a $1 \mathrm{~cm}^{-1}$ spectral resolution. Further details of such surface spectral emissivity can be found in Huang et al. (2016). (b) The surface type classification of Africa in January is based on Huang et al. (2016). The upper rectangle defines the Sahara in this study $\left(20^{\circ}-36^{\circ} \mathrm{N}, 16^{\circ} \mathrm{W}-33^{\circ} \mathrm{E}\right)$ and the lower rectangle defines the Sahel $\left(10^{\circ}-20^{\circ} \mathrm{N}, 18^{\circ} \mathrm{W}-40^{\circ} \mathrm{E}\right)$.

subsequent studies (Sud and Fennessy 1982; Xue and Shukla 1993; Taylor et al. 2002), desertification can increase surface albedo, which causes the surface to absorb less solar energy and leads to a decrease in surface temperature and in sensible heat flux. These changes would then weaken convective activities and decrease convective rainfall, thus constituting a positive feedback mechanism. In all previous studies, the role played by the surface longwave (LW) spectral emissivity has been entirely ignored. Surface emissivity can vary with surface type and spectral wavelengths, as shown in Fig. 1a, which presents surface spectral emissivity for desert, grass, and deciduous forest, based on the dataset developed in Huang et al. (2016). This suggests that changes of surface type can indeed change the surface spectral emissivity. From this perspective, the changes in surface emissivity can potentially alter surface energy processes and affect regional atmospheric circulation, in a manner similar to the changes in surface albedo depicted in Charney et al. (1977).

Figure 1a also shows that, while both grass and deciduous forest can be well approximated as a graybody with an emissivity about 0.98 over the entire LW spectrum, desert surface emissivity exhibits a strong spectral dependence. Desert emissivity can be as low as 0.7 in the mid-infrared window band, a band featured with little gaseous absorption and emission in the atmosphere. However, most general circulation models (GCMs) do not take this spectral dependence of surface emissivity into account and, instead, assume that all surface types are blackbody in the radiation scheme used in the atmospheric module (Chen et al. 2014). Surface upward LW flux is the lower boundary condition for solving the LW radiative transfer in the atmosphere. Given the nature of gaseous absorption and emission, the LW radiative transfer in the atmosphere is highly spectrally dependent. Therefore, the lower boundary condition must include an accurate spectral partitioning of the broadband upward LW flux. Otherwise, the entire atmospheric LW radiative transfer solution begins from an incorrect boundary condition. Such need of correct spectral partitioning of the broadband upward LW flux at the surface warrants the inclusion of spectrally resolved surface emissivity in the radiation scheme of the GCMs. Since the desert has such strong spectral dependence in surface emissivity and is the dominant surface type in the Sahara and Sahel (Fig. 1b), this blackbody assumption in GCMs needs to be re-examined.

Using a realistic surface spectral emissivity dataset and the atmospheric profiles from the ECMWF ERA-Interim reanalysis (Dee et al. 2011), Huang et al. (2016) estimated that such emissivity difference with respect to the blackbody surface assumption can reduce the outgoing longwave radiation (OLR) by as much as $10 \mathrm{~W} \mathrm{~m}^{-2}$ in the Sahara and Sahel. The influence of surface emissivity on climate model simulation was further assessed in Huang et al. (2018), in which they incorporated treatments of surface spectral emissivity into the Community Earth System Model (CESM). Their simulations showed that, compared to the standard CESM simulation, the inclusion 
of surface spectral emissivity can significantly affect the climatology of high-latitude surface temperature and sea ice fraction. They also showed that the simulated surface temperature and precipitation over the Sahara and Sahel is sensitive to the surface spectral emissivity. Since Huang et al. (2018) focused on the high-latitude climate simulation, especially the interactive radiation coupling between the atmosphere and ocean in the polar regions, they did not explore in full depth the mechanisms of how the surface spectral emissivity affects the simulated climate over the Sahara and Sahel. This study is to particularly examine the impact of the inclusion of surface spectral emissivity over the Sahara and Sahel on the simulated regional climate, especially the surface temperature and precipitation.

The remainder of this paper is organized as follows. Section 2 describes the modified version of CESM used in this study and the design of simulation experiments. Section 3 presents the numeric results and physical interpretations. Conclusions and further discussions are then given in section 4 .

\section{Method and simulation experiment design}

\section{a. The modified version of CESM with the treatments of surface spectral emissivity}

Surface spectral emissivity used in this study is taken from Huang et al. (2016), in which a hybrid approach was used to develop a global surface emissivity dataset suitable for the use in weather and climate models. Because few measurements of surface emissivity are available in the far-IR, Huang et al. (2016) employed first-principle calculations to compute the surface spectral emissivities over the entire LW spectrum for several surface types, such as water, ice, and sand with assumed shapes and sizes. Because of the diversity of vegetation types and the practical difficulty measuring index of refraction of each type of vegetation, the surface spectral emissivity of vegetation was taken from Advanced Spaceborne Thermal Emission and Reflection Radiometer (ASTER) Spectral Library version 2.0 (Wilber et al. 1999; Baldridge et al. 2009), namely grass, dry grass, conifer forest, and deciduous forest. Since the ASTER only measured mid-IR emissivity, the far-IR emissivities of these vegetation types were assumed to be constant and equal to the measured emissivities at the longest mid-IR wavelength, that is, $14 \mu \mathrm{m}\left(714 \mathrm{~cm}^{-1}\right)$. In total 11 surface types were defined in Huang et al. (2016). The spectral emissivities of these 11 surface types were then regressed against the Moderate Resolution Imaging Spectroradiometer (MODIS) retrieved surface mid-IR emissivity at eight discrete spectral points to determine the surface type and corresponding surface spectral emissivity at every $0.05^{\circ} \times 0.05^{\circ}$ grid. Then the surface spectral emissivity was averaged onto $0.5^{\circ} \times 0.5^{\circ}$ grids and validated against the mid-IR surface spectral emissivity retrievals from the Infrared Atmospheric Sounding Interferometer (IASI; Zhou et al. 2011). As shown in Huang et al. (2016), the spectral emissivity dataset had a good agreement with the IASI mid-IR retrievals. The root-mean-square difference of band-averaged emissivity over the entire globe was $\sim 0.01$. The largest differences were $\sim \pm 0.05$, occurring over deserts and plateau areas where complicated desert compositions or plateau topography hindered a good agreement between the IASI retrievals and the dataset developed in Huang et al. (2016). More details about the validation of the emissivity dataset can be found in Huang et al. (2016).

Huang et al. (2018) incorporated the aforementioned surface spectral emissivity dataset into CESM version 1.1.1 (Hurrell et al. 2013). The surface spectral emissivity was averaged onto the bandwidths used by the LW radiation scheme in CESM 1.1.1, the RRTMG_LW (Mlawer et al. 1997), and the band-byband surface emissivity was then used in the atmospheric radiative transfer calculation. Note that the broadband upward LW flux at the surface $\left(F_{\text {sfc }}^{\uparrow}\right)$ in the atmospheric model is provided from the surface models of CESM. These surface models assume the surface to be either a blackbody or a graybody with no spectral dependence, and calculate $F_{\text {sfc }}^{\uparrow}$ under such assumption. However, the surface is always assumed to be blackbody in the atmospheric model of the standard CESM. To ensure the conservation of energy between the atmospheric and surface models, the CESM defines surface radiative skin temperature as $T_{\text {skin }}=\left(F_{\text {sfc }}^{\uparrow} / \sigma\right)^{1 / 4}$, where $\sigma$ is the Stefan-Boltzmann constant, and uses $T_{\text {skin }}$ with blackbody assumption in the RRTMG_LW. Huang et al. (2018) incorporated surface spectral emissivity into the RRTMG_LW but not into any surface models in the CESM. To ensure the consistency of $F_{\mathrm{sfc}}^{\uparrow}$ across the different model components, $T_{\text {skin }}$ was redefined as

$$
F_{\mathrm{sfc}}^{\uparrow}=\sum_{i} F_{i}^{\uparrow}=\sum_{i} \varepsilon_{i} \pi\left[\int_{\Delta v_{i}} B_{v}\left(T_{\mathrm{skin}}\right) d v\right]+\sum_{i}\left(1-\varepsilon_{i}\right) F_{i \_\mathrm{sfc}}^{\downarrow},
$$

where $B_{v}\left(T_{\text {skin }}\right)$ is Planck's function at the temperature of $T_{\text {skin }}, \Delta v_{i}$ is the bandwidth of the $i$ th band in the RRTMG_LW, $\varepsilon_{i}$ is the band-averaged surface emissivity of the $i$ th band, $F_{i}^{\uparrow}$ is the surface upward flux of the $i$ th band, and $F_{i \text { sfc }}^{\downarrow}$ is the downward flux of the $i$ th band at the surface as computed by the RRTMG_LW. The 
physical interpretation of Eq. (1) is that both surface emission $\left[\sum_{i} \varepsilon_{i} \pi \int_{\Delta v_{i}} B_{v}\left(T_{\text {skin }}\right) d v\right]$ and reflection of downward flux at the surface $\left[\sum_{i}\left(1-\varepsilon_{i}\right) F_{i_{-} \text {sfc }}^{\downarrow}\right]$ contribute to $F_{\text {sfc }}^{\uparrow}$. This interpretation will be used later for explaining the simulation results. Equation (1) was solved iteratively for $T_{\text {skin. }}$ In other words, compared to the standard CESM, such modification redistributed the broadband $F_{\text {sfc }}^{\uparrow}$ computed by the surface models into the RRTMG_LW spectral bands according to Eq. (1), which adopted more realistic surface spectral emissivity than the blackbody assumption used in the atmospheric model of the standard CESM. This study adopts the same modified version of CESM as in Huang et al. (2018). Further details about this modification and its verification can be found in Huang et al. (2018).

\section{b. Simulation experiment designs}

Since the focus here is to study the impact of surface spectral emissivity in the Sahara and Sahel on the simulated climate, we carry out two sets of parallel CESM simulations. The first set uses the standard CESM (i.e., assuming blackbody surface everywhere in the atmospheric model) and is termed the "CTL" run. The other set uses the modified version of CESM and is termed the "NEW" run. The NEW run assumes blackbody everywhere except for the Sahara $\left(20^{\circ}-36^{\circ} \mathrm{N}, 16^{\circ} \mathrm{W}-33^{\circ} \mathrm{E}\right)$ and the Sahel $\left(10^{\circ}-20^{\circ} \mathrm{N}, 18^{\circ} \mathrm{W}-40^{\circ} \mathrm{E}\right)$, where the surface emissivities of each calendar month are prescribed according to the dataset developed by Huang et al. (2016). Thus, the only difference between the CTL and NEW runs is the surface emissivity specifications over the Sahara and Sahel. Figure 2 shows band-averaged surface emissivity in four RRTMG_LW bands for January. Similar patterns are seen in the surface emissivity maps of other calendar months as well (not shown here). Consistent with what is shown in Fig. 1, surface emissivity in the Sahara and Sahel over the band of 1080$1180 \mathrm{~cm}^{-1}$ is significantly lower than unity and can be as low as 0.6 (Fig. 2c).

Both CTL and NEW simulations are carried out using CESM 1.1.1. These simulations use the "F_2000" component set, in which the Community Atmosphere Model (CAM) is coupled with the Community Land Model (CLM) while sea surface temperatures and sea ice extent are prescribed with climatological monthly values (Hurrell et al. 2008). The vegetation area and density are also prescribed in the CLM with monthly values at the year of 2000. Trace gases and aerosols in the atmosphere are prescribed at the level of year 2000. Solar forcing is also prescribed without year-to-year variation. Both CTL and NEW simulations are carried out for 35 years and the output from the last 30 years is used in the following analysis. The horizontal resolution of these simulations is $1.9^{\circ}$ latitude by $2.5^{\circ}$ longitude and the number of vertical levels in CAM is 26 .

\section{Results and discussion}

Simulated climate over the Sahara and Sahel will be discussed first, followed by the simulated regional climate beyond the Sahara and Sahel.

\section{a. The Sahara and Sahel}

\section{1) DifFERENCES IN SURFACE ENERGY BUdGeT AND NEAR-SURFACE METEOROLOGICAL VARIABLES}

The top three rows of Fig. 3 show the 30-yr mean differences between the NEW and CTL runs in the upward LW flux at the surface (Figs. 3a,c,e) and at the TOA (i.e., OLR; Figs. 3b,d,f). The statistics are also summarized in Table 1. The surface upward LW broadband flux from the NEW run is larger than that from the CTL run over all Sahara grids and a dominant part of the Sahel (Fig. 3a). For the broadband OLR, however, the NEW run simulates a smaller OLR over all grids in the Sahara and Sahel than that from the CTL run (Fig. 3b). The different responses between the surface upward flux and the OLR can be understood as the LW broadband flux is decomposed to each RRTMG_LW band. From Fig. 3c, it becomes clear that the increase of surface upward LW flux from the CTL run to the NEW run originates from the far- $\mathrm{IR}_{2} \mathrm{O}$ rotational band $\left(\sim 10-630 \mathrm{~cm}^{-1}\right)$ as well as $\mathrm{H}_{2} \mathrm{O}$ v2 band $(\sim 1300$ $1900 \mathrm{~cm}^{-1}$; not shown). The contribution from the $\mathrm{H}_{2} \mathrm{O}$ v2 band is much smaller than that from the far-IR band because the total flux of the $\mathrm{H}_{2} \mathrm{O}$ v2 band is smaller than the far-IR band by several factors. Such changes of surface upward flux in these bands, however, have little impact on the OLR due to strong absorption and emission of $\mathrm{H}_{2} \mathrm{O}$ in the atmosphere, as shown in Fig. 3d. In contrast, over the mid-IR window band (in the RRTMG_LW bandwidth, $820-1180 \mathrm{~cm}^{-1}$ ), a decrease in the surface upward flux from the CTL run to the NEW run is seen and such decrease is also seen at the TOA (Figs. 3e,f). This is because atmospheric absorption is limited in the window band. Figure 3 clearly shows that the decrease of the broadband OLR in the NEW run is a result of the reduced outgoing longwave flux in the window band, with little contributions from other spectral bands.

The contrast between the far-IR and window bands in the surface upward flux shown in Figs. $3 \mathrm{c}$ and $3 \mathrm{e}$ can be understood in terms of surface emission and reflection of 
(a) $350-500 \mathrm{~cm}^{-1}$

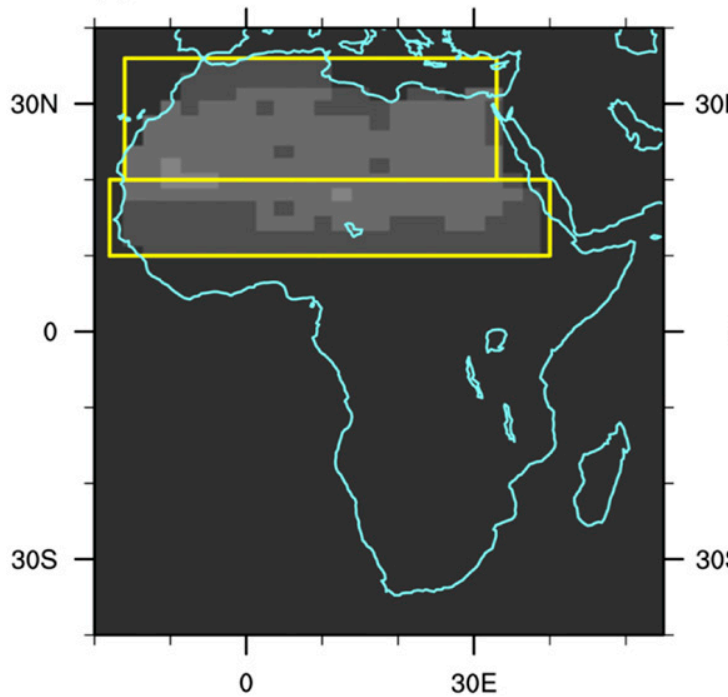

(c) $1080-1180 \mathrm{~cm}^{-1}$ (b) $630-700 \mathrm{~cm}^{-1}$

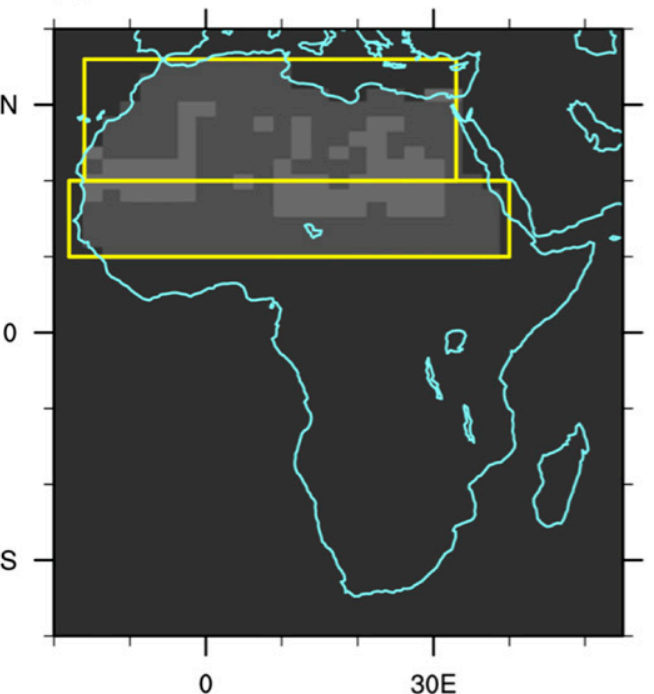

(d) $1800-2080 \mathrm{~cm}^{-1}$
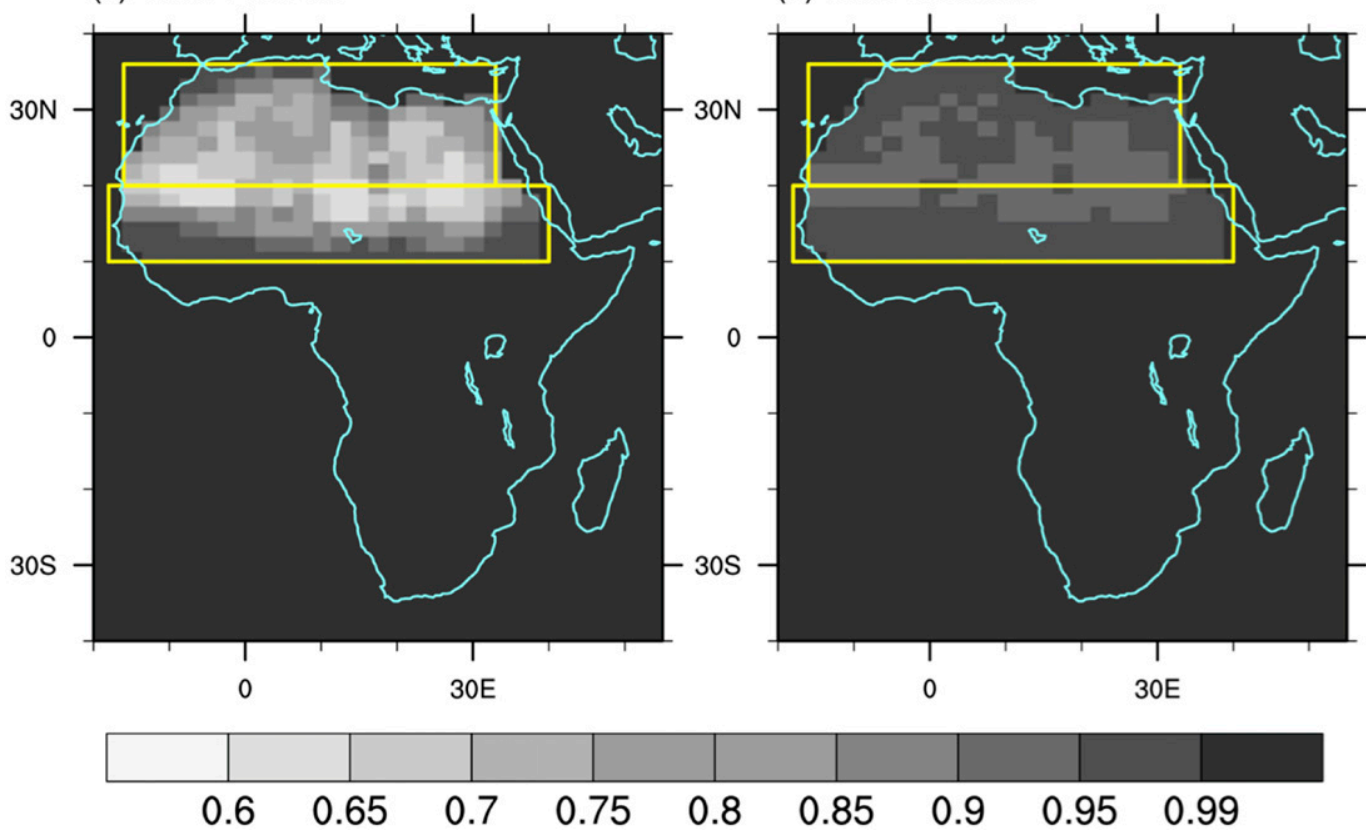

FIG. 2. Surface emissivity in the Sahara and Sahel for four RRTMG_LW bands: (a) $350-500 \mathrm{~cm}^{-1}$ (a band in the far IR); (b) $630-700 \mathrm{~cm}^{-1}$ (a band in the center of the $\mathrm{CO}_{2}$ mid-IR band); (c) $1080-1180 \mathrm{~cm}^{-1}$ (a mid-IR window band); and (d) $1800-2080 \mathrm{~cm}^{-1}$ (a band in the tail of the $\mathrm{H}_{2} \mathrm{O}$ 6.3- $\mu \mathrm{m}$ band). January results are shown here. Other months have similar surface emissivity features in the Sahara and Sahel. The two yellow rectangles define the Sahara and Sahel, respectively. The emissivity data are based on Huang et al. (2016).

downward flux: these two terms consist of surface upward LW flux and are shown at the far right side of Eq. (1). The band-averaged surface emission in the $i$ th band is determined by surface temperature and surface emissivity $\varepsilon_{i}$, and the reflection flux is determined by the downward LW flux at the surface and the reflectivity, which is $\left(1-\varepsilon_{i}\right)$. Over the Sahara and Sahel, the $\varepsilon_{i}$ value of the window band in the NEW run is much lower than that in the CTL run (Fig. 2c). As a result, even though the near-surface temperature increases from the CTL run to the NEW run (Fig. 4; to be discussed later), the smaller $\varepsilon_{i}$ in the NEW run reduces surface emission in the window band compared to the CTL run. Such reduction cannot be compensated by the increase in the 


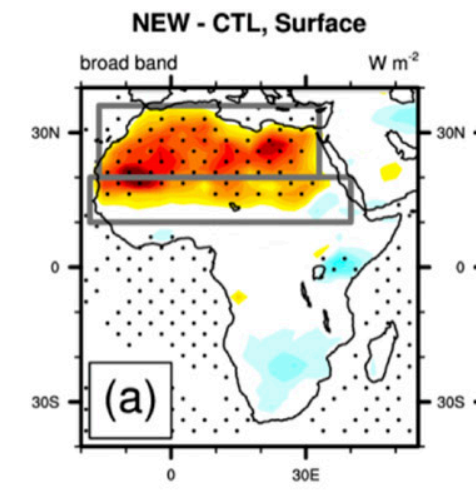

NEW - CTL, TOA
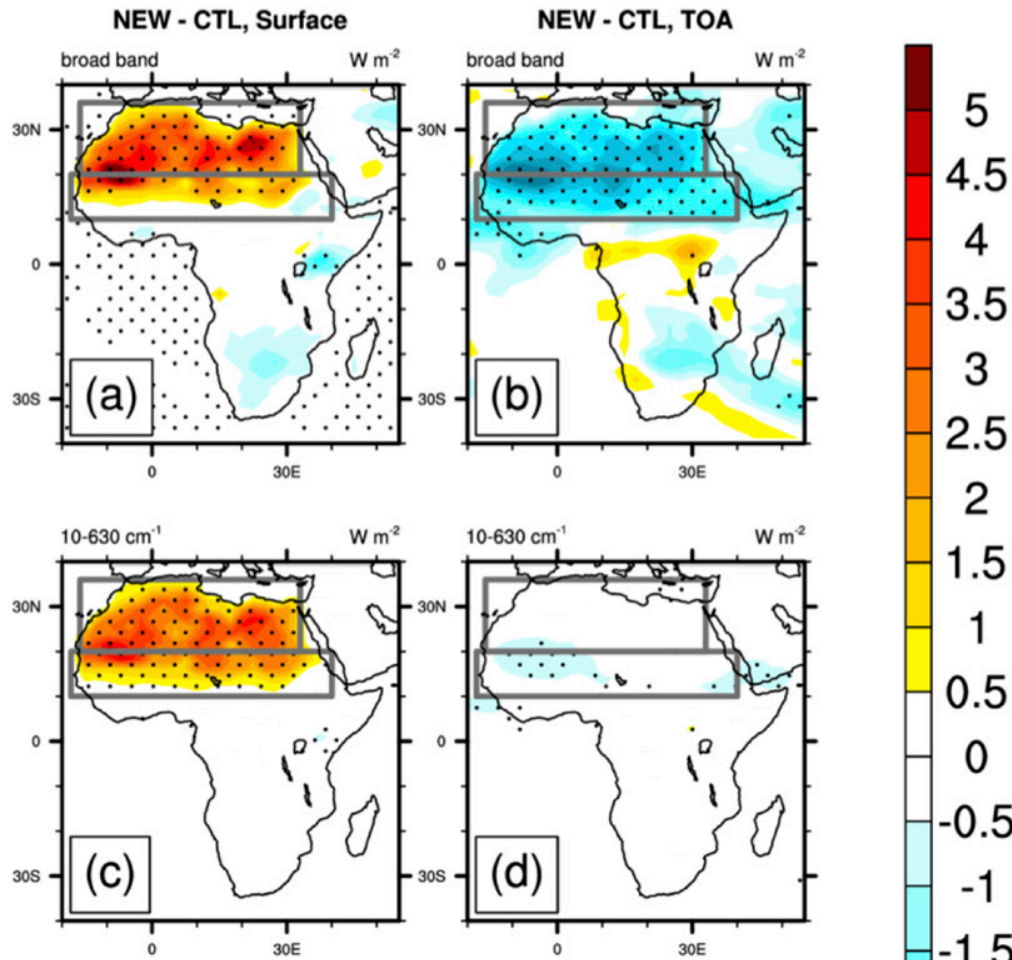

1

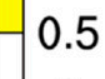

0
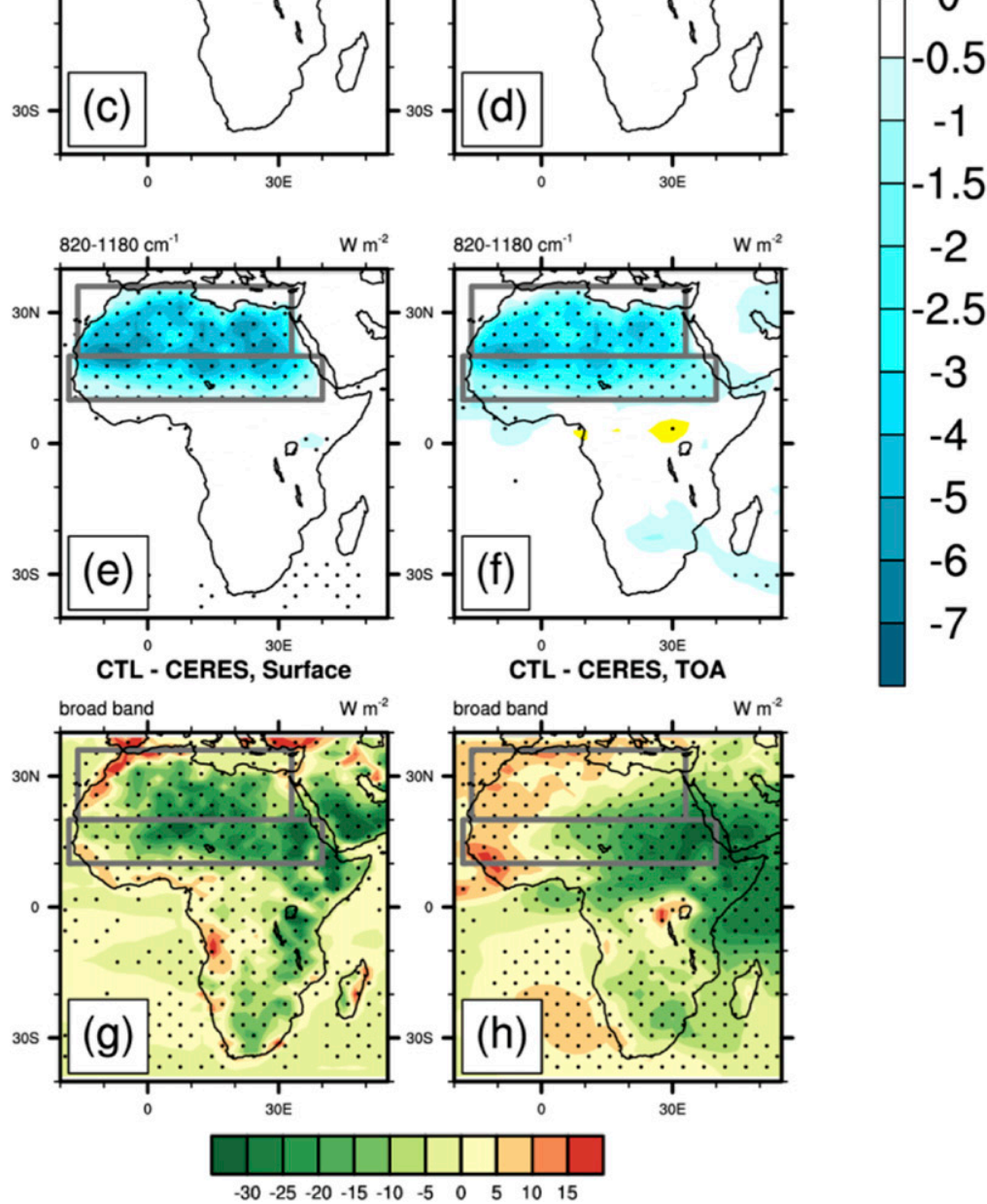

FIG. 3. (a),(b) The upward LW broadband flux differences between the NEW and CTL runs at the surface and at the TOA, respectively. (c),(d) As in (a),(b), but for the far IR (10-630 $\left.\mathrm{cm}^{-1}\right)$. (e),(f) As in (a),(b), but for the window band $\left(820-1180 \mathrm{~cm}^{-1}\right)$. Dotted area indicates that the differences pass the Student's $t$ test with a $5 \%$ significance level. The two gray rectangles define the Sahara and Sahel. (g),(h) The upward LW broadband flux differences between the CTL run and the CERES climatology at the surface and at the TOA, respectively. 
TABLE 1. Simulated energy budget and other key meteorological variables averaged over the Sahara and Sahel from the CTL run and the corresponding differences between the NEW and CTL runs. All results are based on the 30-yr average using the simulations from year 6 to year 35 .

\begin{tabular}{|c|c|c|}
\hline & CTL & $\begin{array}{l}\text { NEW - CTL difference } \\
\text { (mean } \pm \text { standard error) }\end{array}$ \\
\hline \multicolumn{3}{|c|}{ Surface energy budget } \\
\hline LW flux $\uparrow\left(\mathrm{W} \mathrm{m}^{-2} ;\right.$ broadband $)$ & 450.60 & $1.90 \pm 0.39$ \\
\hline $\begin{array}{l}\mathrm{LW} \text { flux } \uparrow\left(\mathrm{W} \mathrm{m}{ }^{-2} ; \text { far-IR band, }\right. \\
\left.\quad 10-630 \mathrm{~cm}^{-1}\right)\end{array}$ & 180.07 & $1.98 \pm 0.09$ \\
\hline $\begin{array}{l}\mathrm{LW} \text { flux } \uparrow\left(\mathrm{W} \mathrm{m}^{-2} \text {; window band, }\right. \\
\left.\quad 820-1180 \mathrm{~cm}^{-1}\right)\end{array}$ & 109.93 & $-3.12 \pm 0.11$ \\
\hline $\mathrm{LW}$ flux $\downarrow\left(\mathrm{W} \mathrm{m}^{-2}\right.$; all sky $)$ & 356.59 & $4.23 \pm 0.50$ \\
\hline LW flux $\downarrow\left(\mathrm{W} \mathrm{m}^{-2}\right.$; clear sky $)$ & 349.91 & $4.02 \pm 0.44$ \\
\hline $\mathrm{LW}$ net $\uparrow\left(\mathrm{W} \mathrm{m}^{-2}\right)$ & 94.01 & $-2.34 \pm 0.50$ \\
\hline $\mathrm{SW}$ flux $\uparrow\left(\mathrm{W} \mathrm{m}^{-2}\right)$ & 76.32 & $-0.71 \pm 0.28$ \\
\hline SW flux $\downarrow\left(\mathrm{W} \mathrm{m}^{-2} ;\right.$ all sky $)$ & 243.15 & $-1.82 \pm 0.65$ \\
\hline SW flux $\downarrow\left(\mathrm{W} \mathrm{m}^{-2}\right.$; clear sky) & 272.14 & $-0.34 \pm 0.14$ \\
\hline SW net $\downarrow\left(\mathrm{W} \mathrm{m}^{-2}\right)$ & 166.83 & $-1.10 \pm 0.37$ \\
\hline Latent heat flux $\left(\mathrm{W} \mathrm{m}^{-2}\right)$ & 24.67 & $1.33 \pm 0.50$ \\
\hline Sensible heat flux $\left(\mathrm{W} \mathrm{m}^{-2}\right)$ & 47.85 & $-0.20 \pm 0.37$ \\
\hline Surface net $\downarrow$ flux $\left(\mathrm{W} \mathrm{m}^{-2}\right)$ & 0.30 & $0.10 \pm 0.04$ \\
\hline \multicolumn{3}{|c|}{ TOA energy budget } \\
\hline LW flux $\uparrow\left(\mathrm{W} \mathrm{m}^{-2}\right.$; broadband $)$ & 268.25 & $-3.27 \pm 0.52$ \\
\hline $\begin{array}{l}\mathrm{LW} \text { flux } \uparrow\left(\mathrm{W} \mathrm{m} \mathrm{m}^{-2} \text {; far-IR band, }\right. \\
\left.10-630 \mathrm{~cm}^{-1}\right)\end{array}$ & 115.01 & $-0.31 \pm 0.15$ \\
\hline $\begin{array}{l}\mathrm{LW} \text { flux } \uparrow\left(\mathrm{W} \mathrm{m}^{-2} \text {; window band, }\right. \\
\left.\quad 820-1180 \mathrm{~cm}^{-1}\right)\end{array}$ & 83.74 & $-2.47 \pm 0.22$ \\
\hline SW flux net $\downarrow\left(\mathrm{W} \mathrm{m}^{-2}\right)$ & 266.15 & $-0.78 \pm 0.25$ \\
\hline \multicolumn{3}{|c|}{ Others } \\
\hline Surface air temperature (K) & 297.34 & $0.32 \pm 0.06$ \\
\hline Temperature at $900 \mathrm{hPa}(\mathrm{K})$ & 294.53 & $0.14 \pm 0.08$ \\
\hline Specific humidity at $900 \mathrm{hPa}\left(\mathrm{g} \mathrm{kg}^{-1}\right)$ & 6.81 & $0.15 \pm 0.06$ \\
\hline Net column radiative cooling rate $\left(\mathrm{W} \mathrm{m}^{-2}\right)$ & 74.92 & $-1.26 \pm 0.23$ \\
\hline Vertical velocity at $500 \mathrm{hPa}\left(\mathrm{hPa} \mathrm{day}^{-1}\right)$ & 13.74 & $-0.58 \pm 0.48$ \\
\hline Convective precipitation rate $\left(\mathrm{mm} \mathrm{day}^{-1}\right)$ & 0.75 & $0.05 \pm 0.03$ \\
\hline Stratiform precipitation rate $\left(\mathrm{mm} \mathrm{day}^{-1}\right)$ & 0.22 & $0.02 \pm 0.01$ \\
\hline
\end{tabular}

reflection of downward flux, because 1) the clear-sky atmosphere has little absorption and emission over the window band and 2) the cloud occurrence is also limited over the Sahara and Sahel. These two facts result in a relatively small downward flux in the window band from the atmosphere. As a result, from the CTL run to the NEW run, the decrease in surface emission dominates over the increase in surface reflection and leads to a decrease in the total surface upward flux in the window band (Fig. 3e). In contrast, although the $\varepsilon_{i}$ value of the far-IR band in the NEW run is smaller than that in the CTL run (Fig. 2a) and also leads to a reduction in surface emission in this band, such reduction is largely compensated by the increase of reflected downward flux. This is because water vapor has strong emission and absorption in the far-IR band, the downward flux at surface $F_{i_{-} \text {sfc }}^{\downarrow}$ is as nearly as large as the surface blackbody emission in the same band [i.e., $\pi \int_{\Delta v_{i}} B_{v}\left(T_{\text {skin }}\right) d v$ in Eq. (1)]. As a result, the increase in surface temperature dominates over the changes in surface emissivity and leads to an increase in surface upward flux in the far-IR band (Fig. 3c). These changes of surface upward LW flux in the far-IR and window bands affect the OLR differently. The changes in the surface upward LW flux in the far-IR band have little effect on the OLR because of the strong atmospheric absorption and emission (Fig. 3d), while the changes in the window band largely influence the OLR because of weak atmospheric absorption and emission (Fig. 3f). Therefore, the reduction of surface upward flux in window band dominates, leading to a decrease in the broadband OLR (Fig. 3b). Figure 3 also indicates that, if a climate model does not take surface spectral emissivity over the Sahara and Sahel into account, its OLR will have an incorrect band-by-band partitioning with excessive flux from the window band.

Figures $3 \mathrm{~g}$ and $3 \mathrm{~h}$ show differences in TOA and surface LW flux climatology between the CTL run and 
(a)

\section{ERA (1979-2017)}

a)

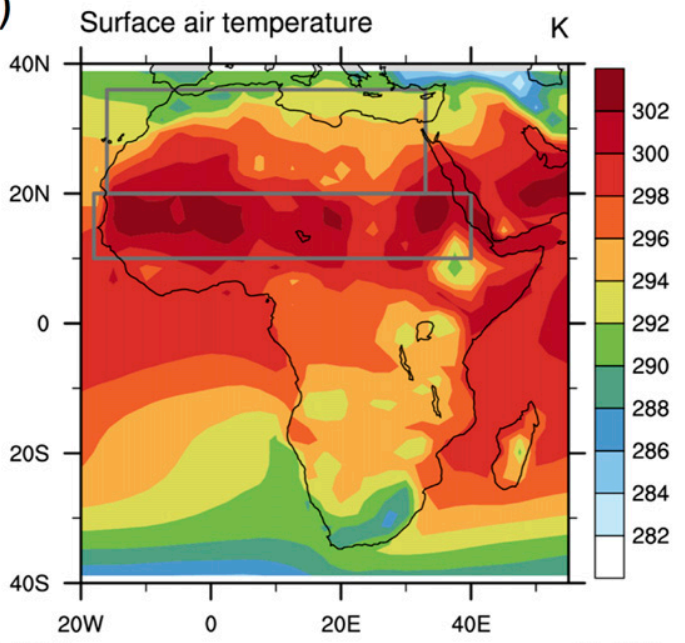

(b)

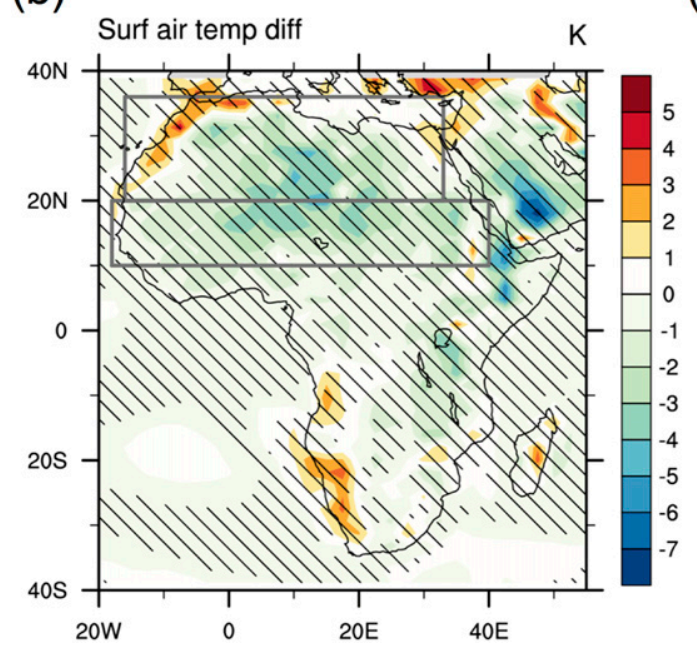

(c)
NEW - CTL

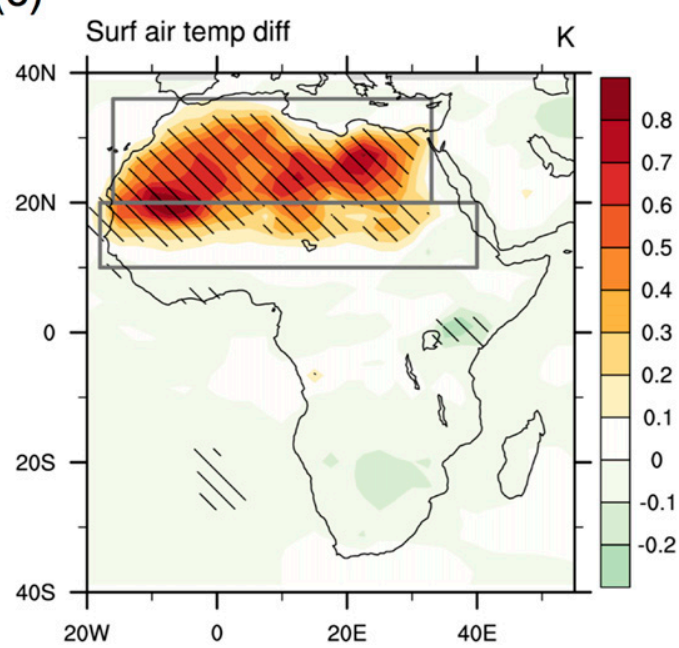

FIG. 4. (a) The long-term mean surface air temperature (SAT) based on ERA-Interim reanalysis from 1979 to 2017. (b) The climatological mean difference of SAT between the CTL run and ERA-Interim. (c) The climatological mean difference of SAT between the NEW and CTL runs. The slashed area indicates that differences pass the Student's $t$ test at 5\% significance level. The two gray rectangles define the Sahara and Sahel.

observations from CERES-EBAF edition 4.0 (Clouds and the Earth's Radiant Energy System-Energy Balanced and Filled; Loeb et al. 2018, Kato et al. 2018). Compared to the CERES surface upward LW flux, the CTL run has large negative biases over the vast majority of the Sahara and Sahel. The inclusion of surface spectral emissivity in the NEW run thus can partially help reduce such biases. As for the OLR, the CTL run has positive (negative) bias in the western (eastern) part of the Sahara and Sahel. Therefore, the inclusion of surface spectral emissivity reduces the positive bias in the west part of the Sahara and Sahel but increases the negative bias in the east part of it.

Figure 4 shows surface air temperature (SAT) climatology from the ECMWF ERA-Interim reanalysis, the difference between the CTL run and ERA-Interim, and the difference between the NEW and CTL runs. The CTL run has colder SAT than ERA-Interim over the vast majority of the Sahara and Sahel, which is consistent with negative biases in the surface upward LW flux shown in Fig. 3g. The SAT in the NEW run is higher than that in the CTL run by up to $0.8 \mathrm{~K}$ in the Sahara and Sahel, and such difference is statistically significant for the majority of the grid points (Fig. 4c). This shows that the inclusion of surface spectral emissivity helps reduce the cold biases of the simulated SAT in the standard CESM.

The NEW-CTL differences in surface energy budget terms are shown in Fig. 5. Four terms in surface energy budget are examined here, namely net upward LW flux, 

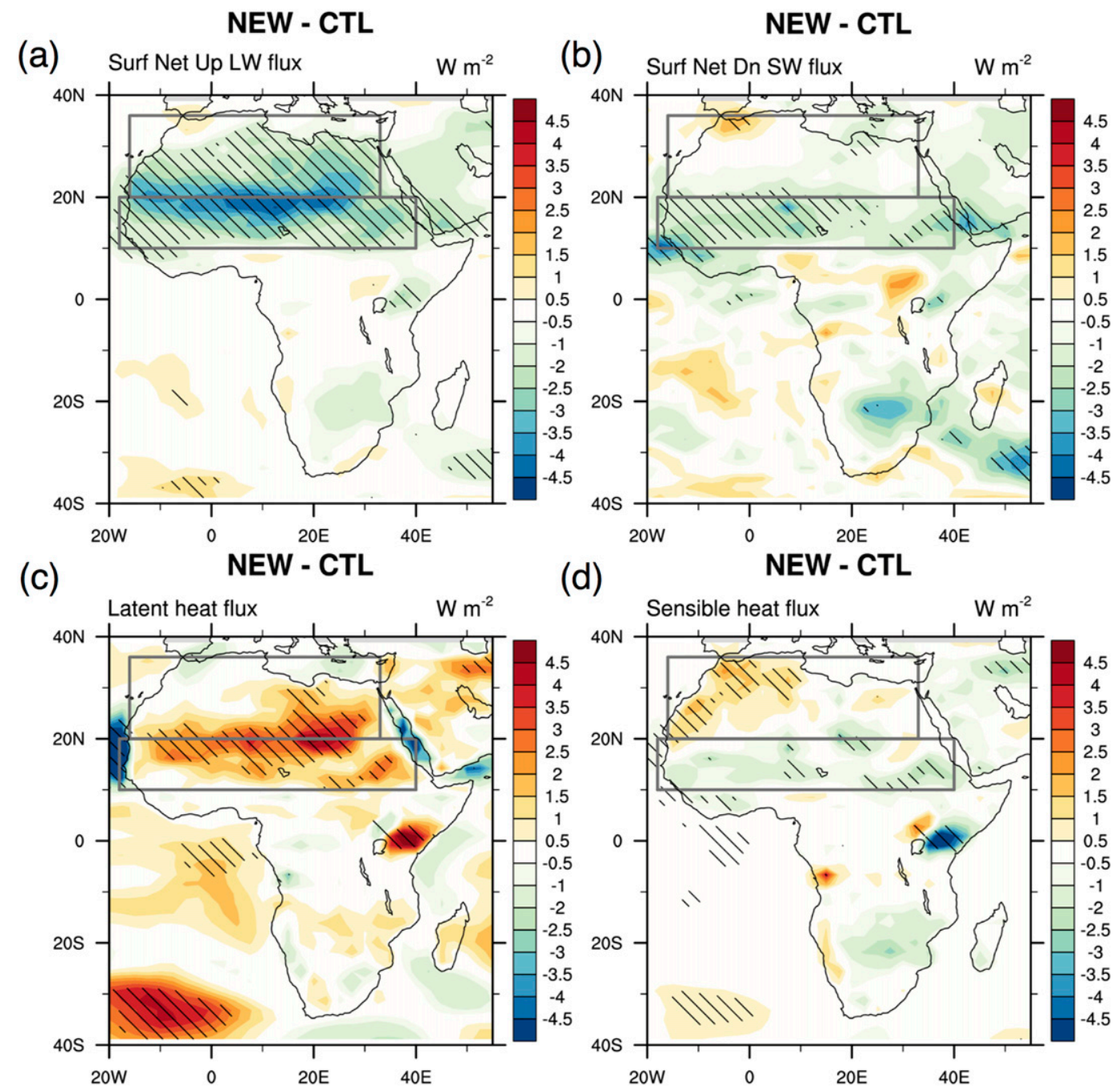

FIG. 5. Differences in surface energy budgets between the NEW and CTL runs. (a) Surface net LW flux (upward positive). (b) Surface net SW flux (downward positive). (c) Latent heat flux. (d) Sensible heat flux. The latent heat and sensible heat fluxes are defined as positive out of the surface. All results are based on 30-yr climatologies and slash area indicates 5\% significance level. The two gray rectangles define the Sahara and Sahel.

net downward shortwave (SW) flux, latent heat flux, and sensible heat flux (defined as positive upward). Although the NEW run has a larger surface upward LW flux over the Sahara and Sahel than the CTL run (Fig. 3a), the net upward LW flux decreases in the NEW run from the CTL run (Fig. 5a). This suggests that the downward LW flux increases in the NEW run and such increases outweigh the increase of surface upward LW flux. The decrease in surface net LW flux is largely compensated by an increase in latent heat flux (Fig. 5c) while the contributions from the sensible heat flux and net downward SW flux are secondary (Figs. 5b,d). The total difference in net surface energy balance is only $0.1 \mathrm{~W} \mathrm{~m}^{-2}$ over the entire Sahara and Sahel (Table 1). An increase of latent heat flux implies increased evaporation.
A further look of the NEW-CTL difference in the planetary boundary layer can explain the increase in downward LW flux at the surface in the NEW run.

Figures $6 \mathrm{a}$ and $6 \mathrm{~b}$ show the differences between the NEW and CTL runs in temperature and in humidity at $900 \mathrm{hPa}$, respectively. Differences in regionally averaged temperature and humidity profiles are shown in Figs. $6 c$ and $6 d$, respectively. In the Sahara, the NEW run has a slightly warmer boundary layer (up to $0.5 \mathrm{~K}$ ) than the CTL run. The temperature difference between the NEW and CTL run monotonically decreases from the boundary layer to $500 \mathrm{hPa}$ and then oscillates around zero. In the Sahel, the temperature difference is much smaller. In contrast, the humidity differences are unanimously positive for both the Sahara and Sahel and are 

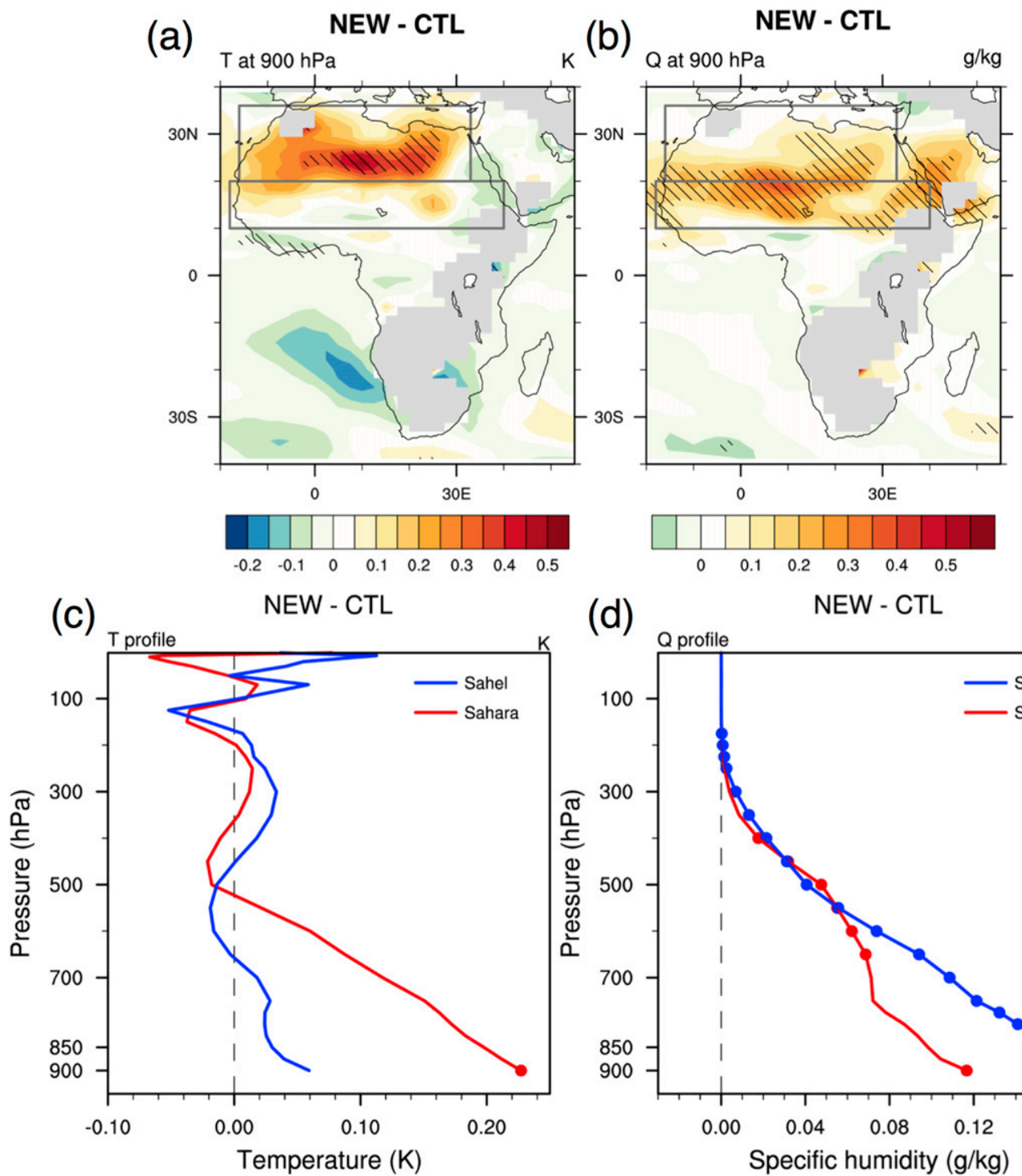

(d)

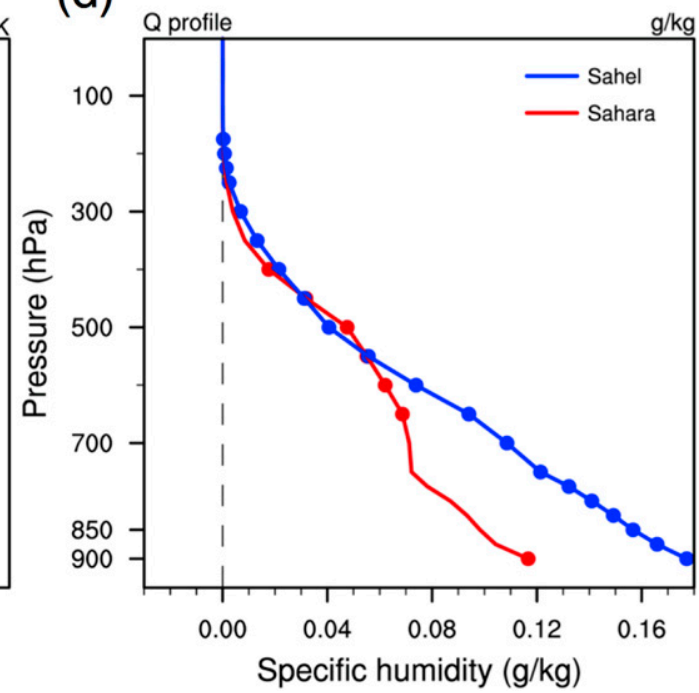

FIG. 6. (a) The long-term temperature difference at $900 \mathrm{hPa}$ between the NEW and CTL runs. (b) As in (a), but for the specific humidity at $900 \mathrm{hPa}$. Slashed area indicates $5 \%$ significance level. The two rectangles define the Sahara and Sahel. (c) The temperature difference from $900 \mathrm{hPa}$ to the TOA between the NEW and CTL runs averaged over the Sahara (red) and Sahel (blue). (d) As in (c), but for the specific humidity. Dots indicate the levels where the differences pass the Student's $t$ test at $5 \%$ significance level.

statistically significant for all tropospheric levels in the Sahel and for the majority of upper and middle tropospheric levels in the Sahara (Fig. 6d). The NEW - CTL difference in $900-\mathrm{hPa}$ specific humidity is $0.18 \mathrm{~g} \mathrm{~kg}^{-1}$ for the Sahel and $0.12 \mathrm{~g} \mathrm{~kg}^{-1}$ for the Sahara, respectively. As discussed later, these wetter and hotter boundary layers in the NEW run can contribute to differences in the precipitation.

Table 1 summarizes the NEW-CTL differences for the energy budget terms and other key climate variables, averaged over the Sahara and Sahel. The differences shown in Figs. 4-6 can be used to help understand the surface energy budget differences in Table 1. Both simulations can be deemed as attaining energy balance at the surface in the Sahara and Sahel: the net surface downward heat flux is $0.30 \mathrm{~W} \mathrm{~m}^{-2}$ in the CTL run and $0.40 \mathrm{~W} \mathrm{~m}^{-2}$ in the NEW run. The NEW run has a larger surface upward LW broadband flux by $1.90 \mathrm{~W} \mathrm{~m}^{-2}$. The downward LW flux at the surface in the NEW run is increased by $4.23 \mathrm{~W} \mathrm{~m}^{-2}$, which is primarily due to a warmer and wetter boundary layer in the NEW run that emits more IR radiation downward. As a result, the net 
(a)
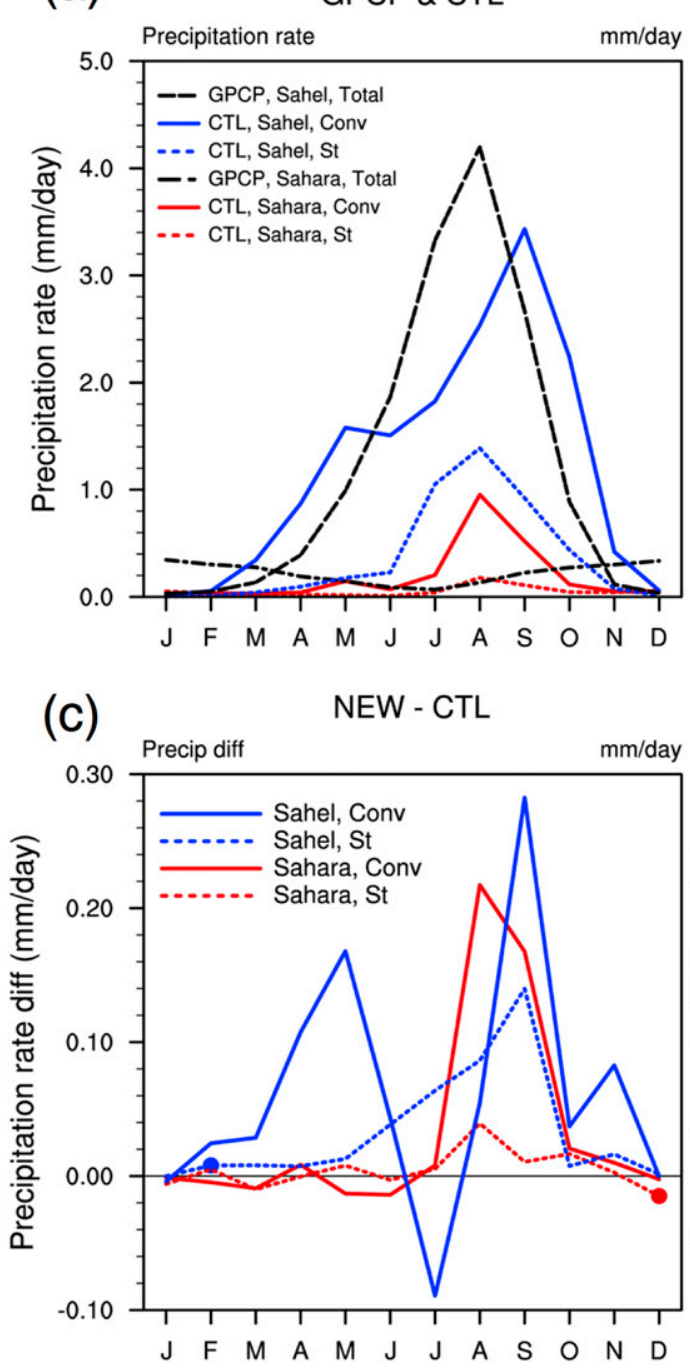

(b)

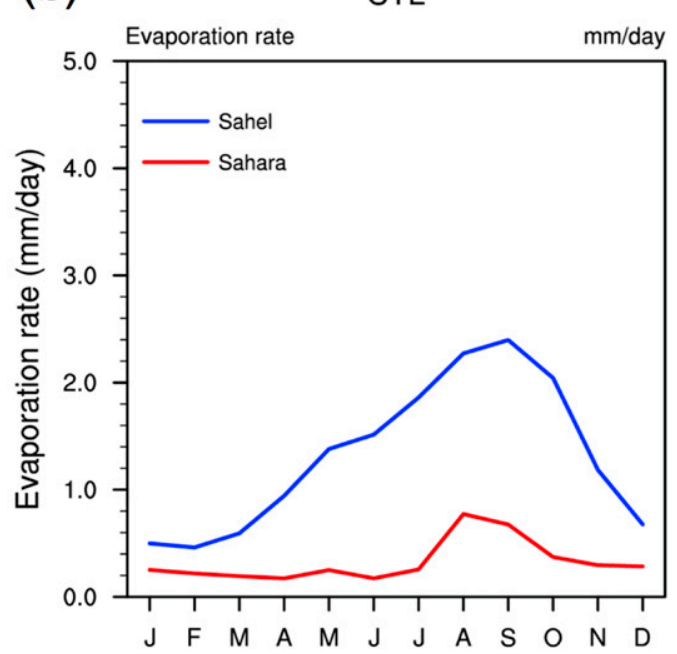

(d)

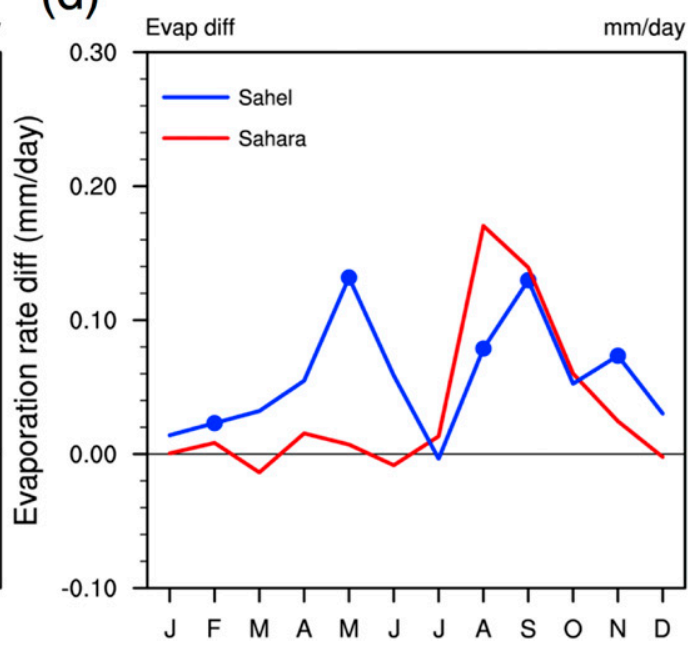

FIG. 7. (a) The mean seasonal cycle of precipitation over the Sahara and Sahel from GPCP observations (black lines) and from the CTL run. The convective and stratiform precipitations from the CTL run are plotted separately. (b) The mean seasonal cycle of evaporation rate as simulated by the CTL run for the Sahara (red) and Sahel (blue). (c) As in (a), but for the differences between the NEW and CTL runs. (d) As in (b), but for the difference between the NEW and CTL runs. Evaporation rate is converted from latent heat flux. Dots in (c) and (d) indicate 5\% significance level.

upward LW flux at the surface is reduced by $2.34 \mathrm{Wm}^{-2}$. Note that simulated clouds in these two runs contribute little to the increase of downward LW flux at the surface because the NEW-CTL difference in all-sky downward LW flux at the surface is almost the same as the difference in clear-sky downward LW flux at the surface (4.23 vs $4.02 \mathrm{~W} \mathrm{~m}^{-2}$ ). On the other hand, the net SW downward flux is reduced by $1.10 \mathrm{~W} \mathrm{~m}^{-2}$ and such reduction is largely caused by the differences in clouds because the NEW-CTL differences in clear-sky downward SW flux at surface is only reduced by $0.34 \mathrm{~W} \mathrm{~m}^{-2}$ (The change in simulated cloud fields will be elaborated on in the next subsection). Combining the LW and SW flux together, the net upward radiative flux at the surface is reduced by $1.24 \mathrm{~W} \mathrm{~m}^{-2}$ from the CTL run to the NEW run. As a compensation, the upward latent heat flux is increased by $1.33 \mathrm{~W} \mathrm{~m}^{-2}$, implying more evaporation in the NEW run, which is consistent with the warmer boundary layer shown in Fig. 6. The slightly warmer boundary layer in the NEW run is also consistent with a reduction of sensible heat flux by $0.2 \mathrm{~W} \mathrm{~m}^{-2}$.

\section{2) DIFFERENCES IN PRECIPITATION AND CLOUD AMOUNT}

Figure 7a shows the seasonal cycle of precipitation in the Sahara and in the Sahel from the CTL run and the 
Global Precipitation Climatology Project version 2.3 (GPCP; Adler et al. 2003). Compared to the GPCP, the CTL run can capture the seasonal cycle of precipitation in the Sahel reasonably well, but in the Sahara it exhibits excessive rain from July to September. Figure 7a also shows that in both regions the convective precipitation dominates over the stratiform precipitation in the CTL run. Simulated seasonal cycle of latent heat flux (Fig. 7b; shown in terms of evaporation rate in $\mathrm{mm} \mathrm{day}^{-1}$ ) clearly shows that the unrealistic rainfall in July-September in the Sahara is related to the latent heat flux.

Figure $7 \mathrm{c}$ shows the NEW-CTL difference in precipitation rate as a function of calendar month, for convective and stratiform rainfall. In the Sahara, an increased precipitation can be seen from July to September, especially in August. Moreover, such precipitation increase is virtually all due to the increase in convective rainfall, with the largest value happening in August $\left(0.22 \mathrm{~mm} \mathrm{day}^{-1}\right.$, or $\sim 23 \%$ increase from the August climatology of the CTL run). In the Sahel, the difference in precipitation occurs in both rainy and dry seasons and is also dominated by convective rainfall change. Unlike in the Sahara, the difference in stratiform precipitation is nonnegligible, especially in the rainy season. The convective precipitation difference in the Sahel has two distinct peaks: one in May $\left(0.17 \mathrm{~mm} \mathrm{day}^{-1} ; 11 \%\right.$ increase $)$ and the other in September $\left(0.28 \mathrm{~mm} \mathrm{day}^{-1} ; 8 \%\right.$ increase). Thus, the percentage change of precipitation due to inclusion of surface spectral emissivity is much larger in the Sahara than in the Sahel. Figure $7 \mathrm{~d}$ shows the monthly-mean difference of latent heat fluxes between the NEW and CTL runs for the Sahara and Sahel, respectively. The monthly variations of such latent heat flux differences are well correlated with the corresponding precipitation differences in Fig. 7c. Moreover, the latent heat flux difference in the Sahara can explain almost all of the precipitation difference in the same region (Fig. 7c vs Fig. 7d) but it is not the same for the Sahel. This implies that the precipitation changes in the Sahara are almost entirely due to enhanced local evaporation but in the Sahel moisture flux from other regions must have contributed significantly to rainfall difference. Together with temperature and humidity differences shown in Figs. 4 and 6, this suggests that using more realistic surface spectral emissivity for the Sahara and Sahel in the CESM leads to more evaporation and more favorable atmospheric conditions for convection, resulting in more convective precipitation. Such precipitation increase is particularly notable during the boreal summer in the Sahara, exacerbating the wet bias over the Sahara in the standard CESM.

Figure 8 shows the seasonal cycle of simulated cloud fraction by the CTL run and the difference between the NEW and CTL runs, for both the Sahara and Sahel. As expected, clouds are infrequent over the Sahara throughout the entire year (Fig. 8a), with the monthlymean cloud fraction at each layer consistently less than $10 \%$. Comparing the NEW run with the CTL run, there is an increase in cloud fraction up to $2 \%$ in the NEW run throughout the troposphere in August and September over the Sahara, consistent with the peak of precipitation increase shown in Fig. 7c. Over the Sahel, high clouds dominate almost every month while middle and low clouds only occur frequently during the rainy season from July to September (Fig. 8b). Positive cloud amount differences between the NEW and CTL runs are seen in virtually all tropospheric layers in the Sahel (Fig. 8d), especially the low-level clouds in May and September, which are statistically significant at $5 \%$ level, consistent with the large increase of precipitation in these 2 months (Fig. 7c).

Figures 7 and 8 suggest that the cloud fraction changes between the NEW and CTL runs vary with season and are well correlated with the precipitation changes and latent heat flux changes. Although not all differences shown in the two figures pass the Student's $t$ test at $5 \%$ significance level, together with Figs. 4 and 6 they delineate a consistent response to the inclusion of surface spectral emissivity in the Sahara and Sahel: the surface air temperature is higher in the NEW run than in the CTL run and the boundary layer becomes warmer and more humid. These lead to more evaporation from the surface and accordingly more convective precipitation. Figure 7 also indicates that the change in the Sahel precipitation is not solely due to convective rainfall and cannot be explained by local evaporation changes alone, indicating changes of moisture convergence and thus possible change of regional circulation due to the inclusion of surface spectral emissivity. This motivates us to look at regional changes beyond the Sahara and Sahel.

\section{b. Regional changes beyond the Sahara and Sahel}

This subsection examines how the inclusion of realistic surface spectral emissivity in the Sahara and Sahel affects simulated climate in adjacent areas. Figure 9 shows the GPCP observed mean precipitation and Fig. 10 shows the vertical velocity at $500 \mathrm{hPa}\left(\omega_{500}\right)$ climatology based on the ECMWF ERA-Interim reanalysis. Also shown in these two figures are the difference between the CTL run and the observations as well as the difference between the NEW and CTL runs. The CTL run overestimates the precipitation over the majority of the African continent (Fig. 9b). But for the west part of the Sahel and its south coast (i.e., part of the African ITCZ in the boreal summer) the CTL run underestimates precipitation by $1-2 \mathrm{~mm}^{-1}$ day $^{-1}$. The NEW run can reduce such negative bias in precipitation by $\sim 0.3 \mathrm{~mm} \mathrm{day}^{-1}$ and 
(a)
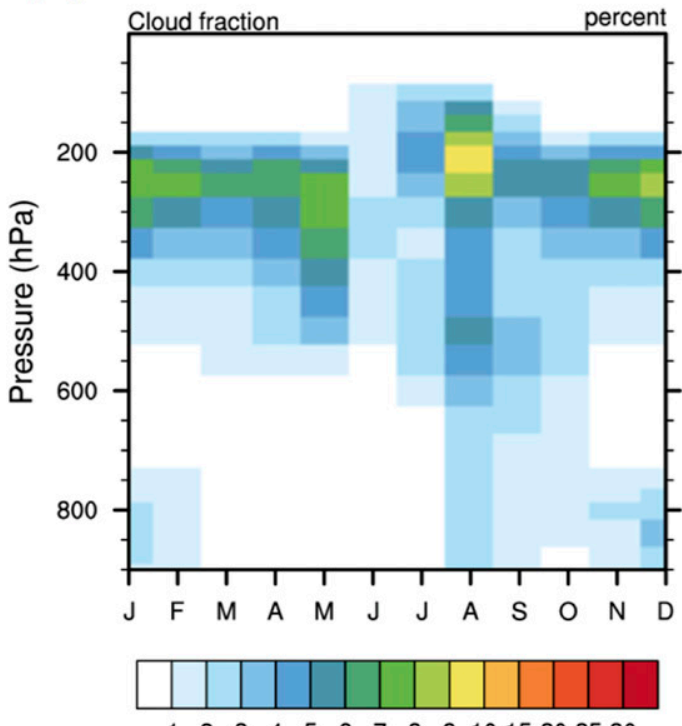

$\begin{array}{lllllllllll}1 & 2 & 3 & 4 & 5 & 6 & 7 & 8 & 9 & 10 & 15202530\end{array}$

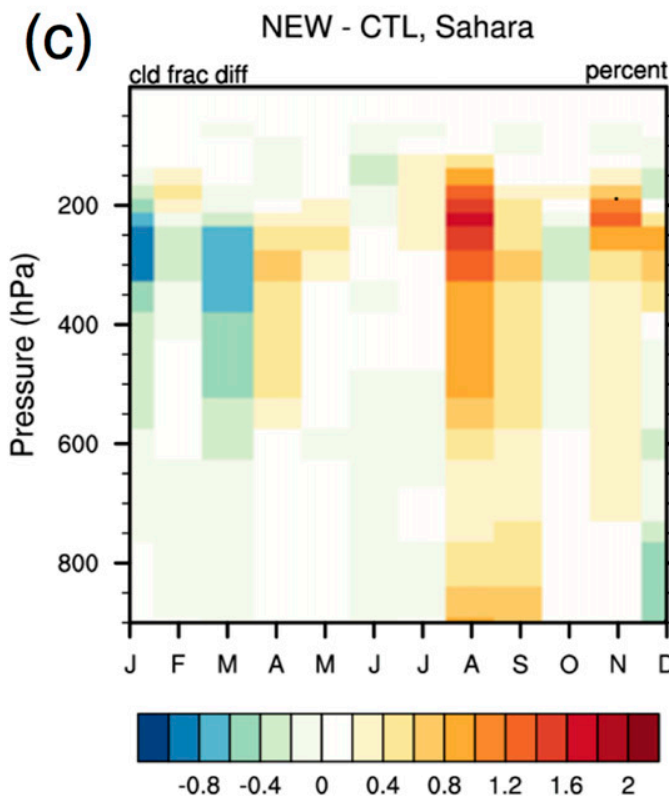

(b) CTL, Sahel
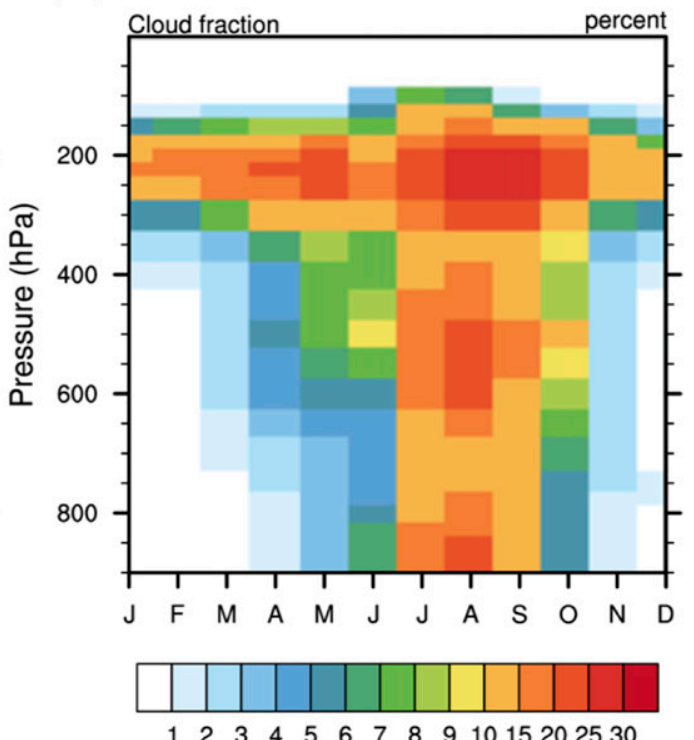

(d) NEW - CTL, Sahel
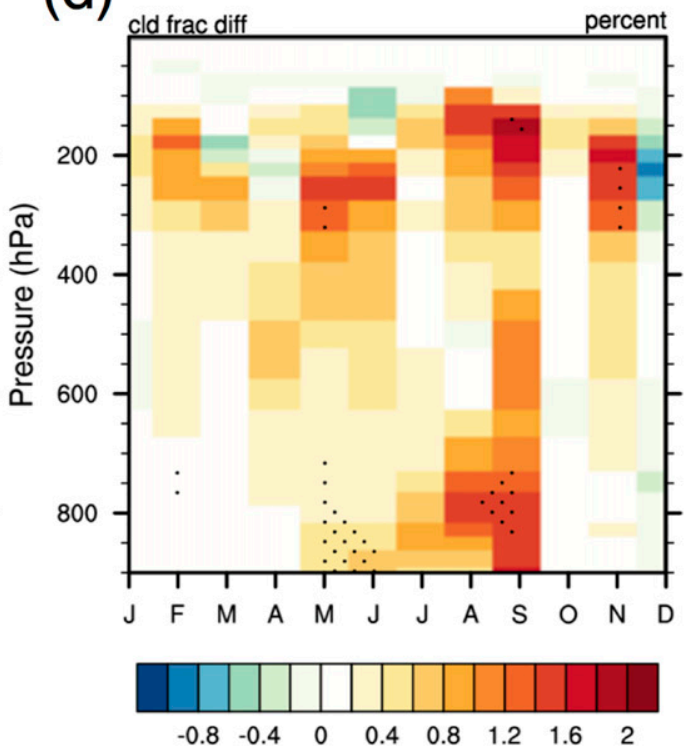

FIG. 8. (a) Mean seasonal cycle of simulated cloud fraction in each vertical layer by the CTL run for the Sahara. (b) As in (a), but for the Sahel. (c) As in (a), but for the difference between the NEW and CTL runs. (d) As in (c), but for the difference in the Sahel. Black dots indicate $5 \%$ significance level.

the difference from the CTL run is statistically significant (Fig. 9c). Over the same regions, Fig. 10c shows statistically significant negative difference in $\omega_{500}$ between the NEW and CTL runs, suggesting more ascending motions in the NEW run and thus supporting the rain rate difference shown in Fig. 9c. Such improved precipitation simulation is in contrast to the exacerbation of positive precipitation bias in the east part of the Sahara and the majority of the Sahel (Figs. 9b,c), as discussed in the previous subsection. The differences in $\omega_{500}$ over the Sahara and north part of the Sahel, although positive, are not statistically significant, likely owing to the large yearto-year fluctuation of vertical velocity. These results indicate that changing the surface spectral emissivity over 
(a)

\section{GPCP (1979-2017)}
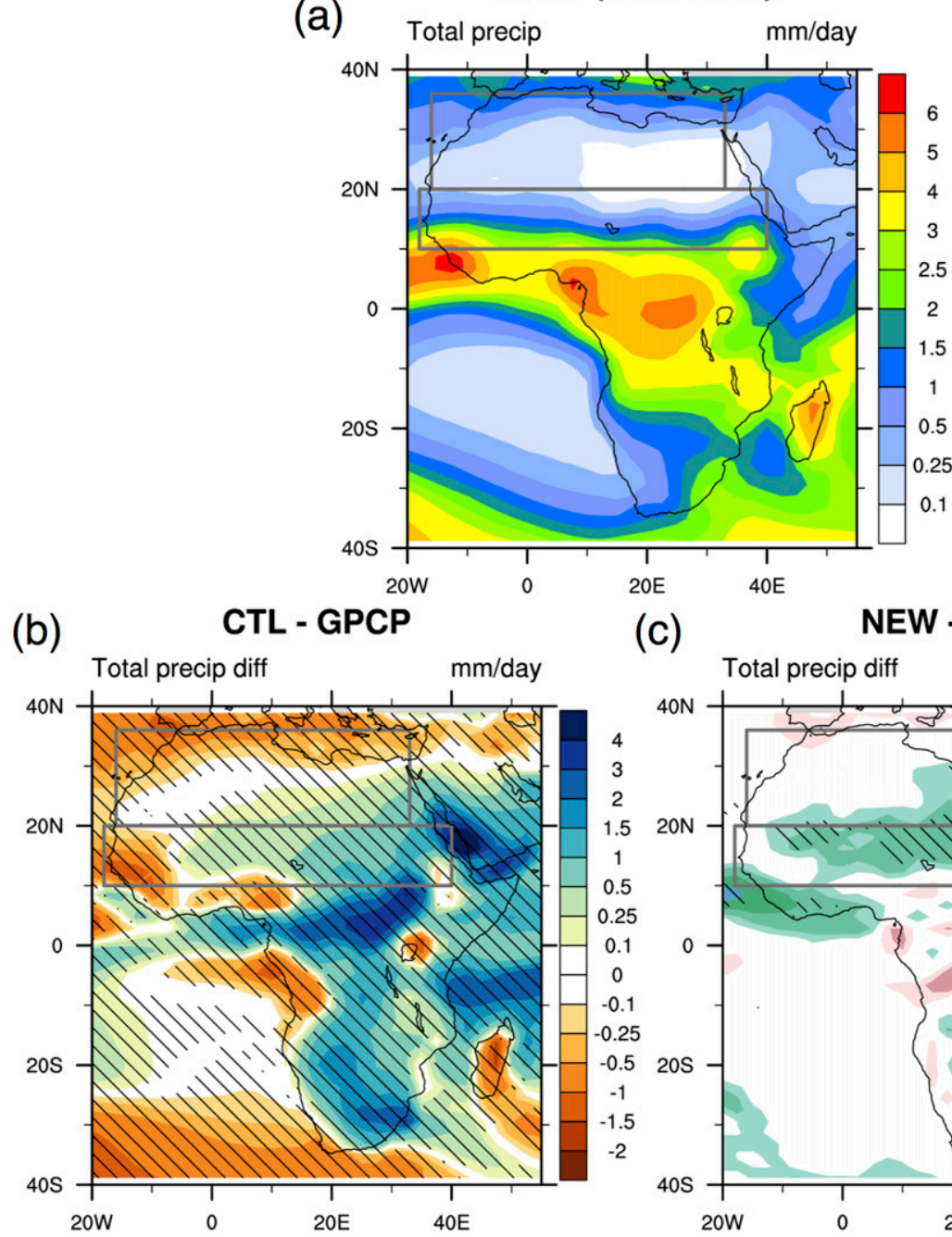

(c)

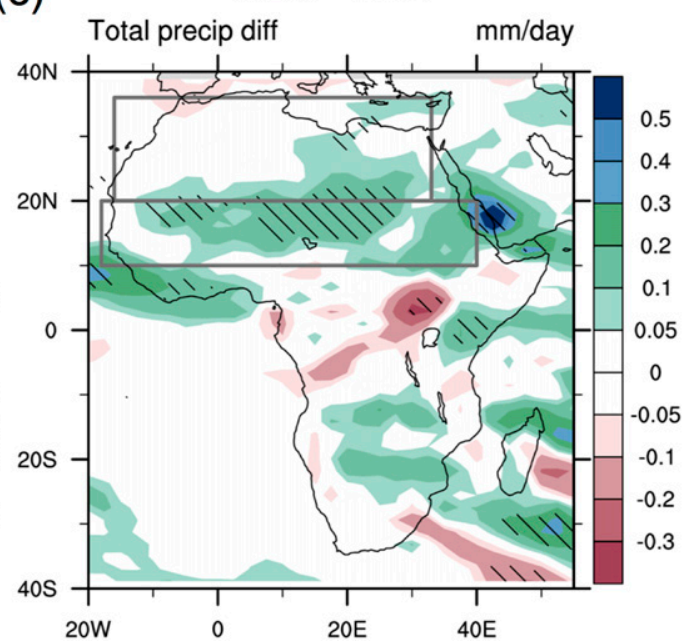

FIG. 9. (a) Observed mean precipitation based on the GPCP climatology from 1979 to 2017. (b) The difference of long-term mean precipitation rate between the CTL run and GPCP. (c) As in (b), but for the differences between the NEW and CTL runs. The slashed area indicates 5\% significance level. The two gray rectangles define the Sahara and Sahel.

the Sahara and Sahel can lead to statistically significant changes in precipitation and $\omega_{500}$ over the adjacent regions, especially south to the Sahel. Such changes can partially address the dry biases in the CTL run with respect to the observations. Meanwhile, the wet bias in the Sahara and Sahel is amplified as a result of more realistic representation of surface emissivity, suggesting that some compensating biases in the standard CESM are masked by unrealistic representation of surface spectral emissivity.

Figure 9c also indicates that the NEW run has larger annual mean precipitation than the CTL run over most of West Africa $\left(10^{\circ} \mathrm{W}-10^{\circ} \mathrm{E}\right)$, from the coastal region north of the Gulf of Guinea to the lower boundary of the
Sahara around $20^{\circ} \mathrm{N}$. The choice of $10^{\circ} \mathrm{W}-10^{\circ} \mathrm{E}$ is to be consistent with geographical regions defined in previous studies about West Africa (e.g., Nicholson and Grist 2003; Thorncroft et al. 2011). Precipitation in West Africa is strongly associated with local evaporation as well as moisture transport from outside regions (Gong and Eltahir 1996; Nieto et al. 2006; Thorncroft et al. 2011). Thus, we further examine the individual contributions from local evaporation and moisture transport to such precipitation changes over different sectors within West Africa. Figure 11 shows the mean seasonal cycles of NEW-CTL differences in precipitation rate, evaporation rate as converted from latent heat flux, and precipitation minus evaporation rate $(P-E$, a proxy of 
(a)

ERA (1979-2017)
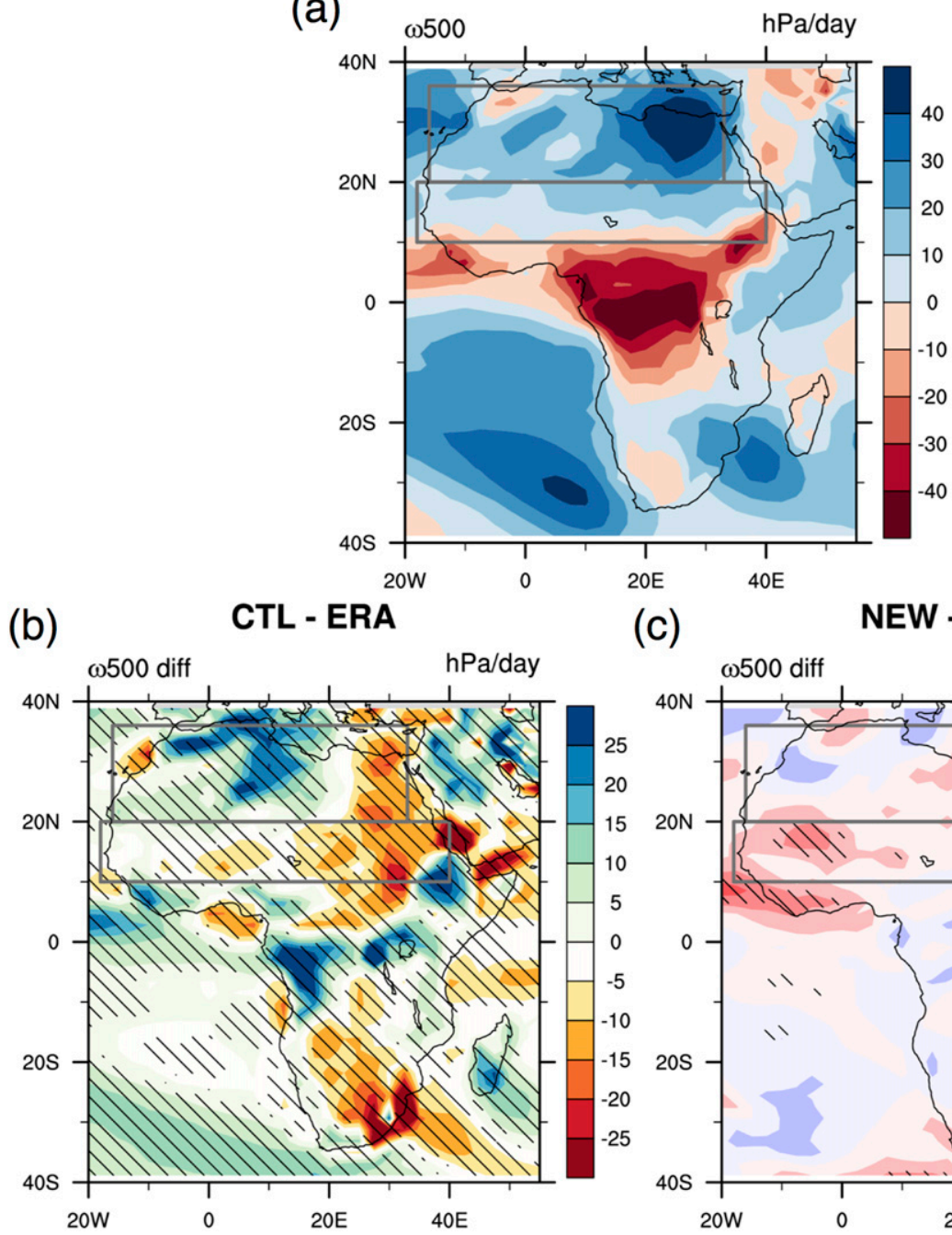

(c)

NEW - CTL

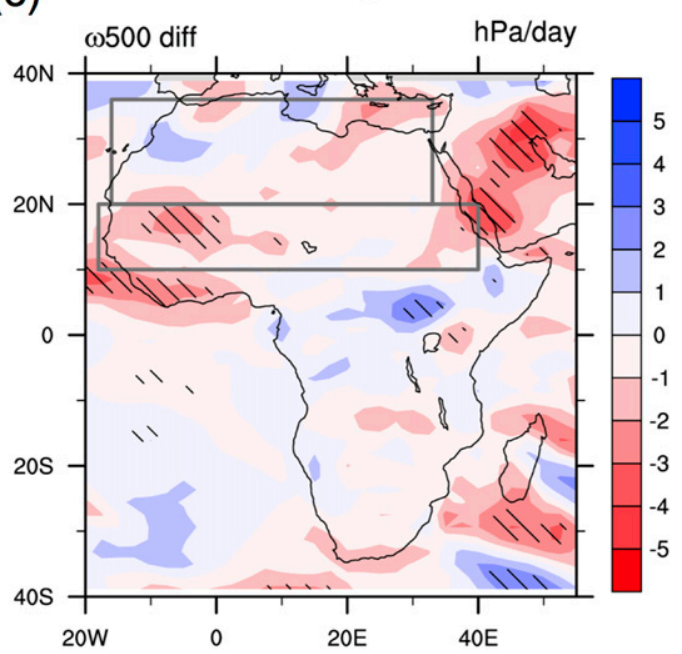

FIG. 10. As in Fig. 4, but for vertical velocity at $500 \mathrm{hPa}$.

moisture flux convergence) for three sectors in West Africa, namely the Sahara sector $\left(20^{\circ}-30^{\circ} \mathrm{N}\right)$, the Sahel sector $\left(10^{\circ}-20^{\circ} \mathrm{N}\right)$, and the Guinea coast sector (including Gulf of Guinea and the coastal region north of it; $\left.10^{\circ} \mathrm{S}-10^{\circ} \mathrm{N}\right)$. The precipitation rate increases over the Sahara sector and is mainly due to the increase in local evaporation rate (Fig. 11a), consistent with the changes in precipitation and latent heat flux over the entire Sahara (Figs. 7c,d). Difference in the moisture flux convergence, as represented by difference in $P-E$, contributes little to the precipitation difference. The Sahara is a region featuring large-scale subsidence (Fig. 10a) of Hadley circulation and thus low-level circulation is dominated by divergence instead of convergence, which can help explain the dominance of local evaporation for such simulated precipitation differences.
For the Sahel sector in West Africa (Fig. 11b), differences in evaporation and moisture flux convergence contribute almost equally to the difference in precipitation in April and May. From July to September when the ITCZ moves northward to the Sahel sector, the difference in moisture flux convergence is more responsible for the change in precipitation than the difference in local evaporation. Such findings are consistent with previous studies that use regional climate models to examine Sahel precipitation (e.g., Noble et al. 2014, 2017). For the Guinea coast sector where surface emissivity is not changed from the CTL to the NEW runs, differences in precipitation closely track the differences in moisture flux convergence for all calendar months, with negligible contributions from local evaporation. The fact that the dominant contributor to the 

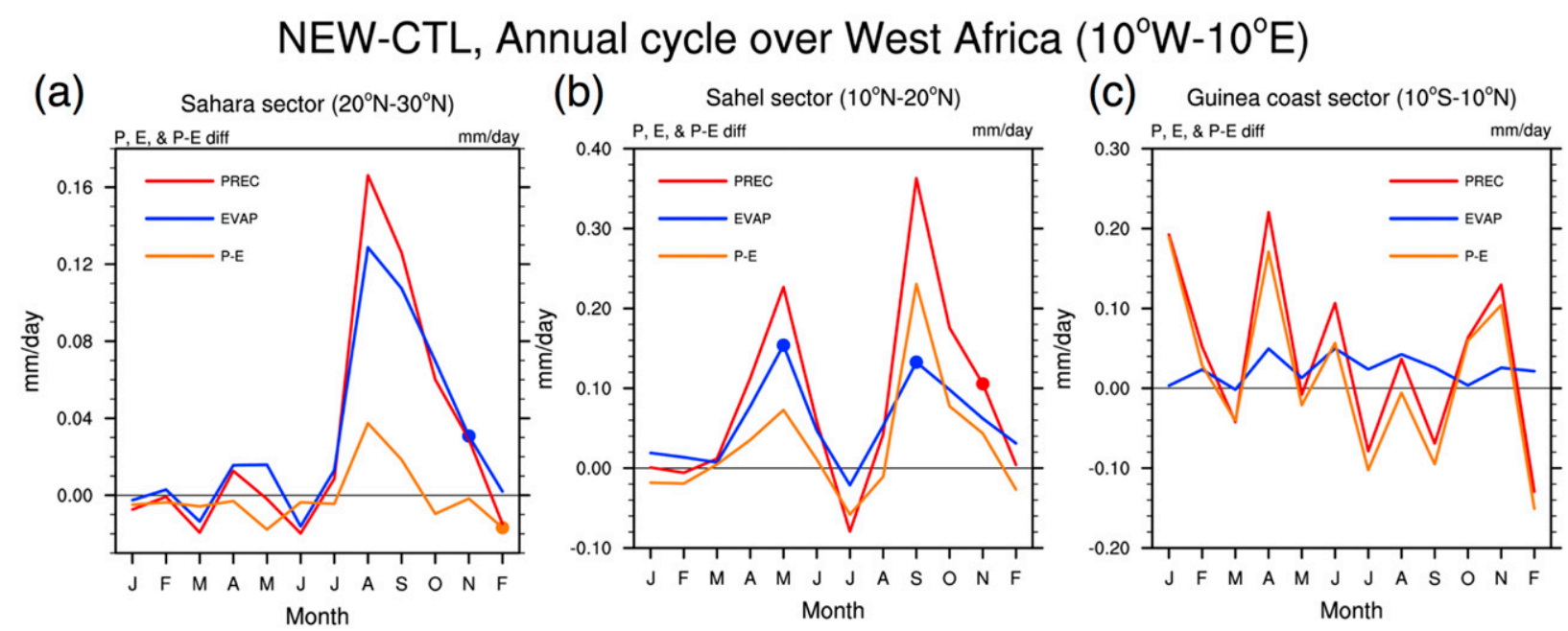

FIG. 11. (a) Mean seasonal cycles of the differences between the NEW and CTL runs in precipitation rate (red), evaporation rate (blue), and in precipitation minus evaporation rate $\left(P-E\right.$; orange). All are averaged over the Sahara sector of West Africa $\left(20^{\circ}-30^{\circ} \mathrm{N}, 10^{\circ} \mathrm{W}-\right.$ $\left.10^{\circ} \mathrm{E}\right)$. (b) As in (a), but for the Sahel sector $\left(10^{\circ}-20^{\circ} \mathrm{N}, 10^{\circ} \mathrm{W}-10^{\circ} \mathrm{E}\right)$. (c) As in (a), but for the Gulf of Guinea and the coastal region north of it $\left(10^{\circ} \mathrm{S}-10^{\circ} \mathrm{N}, 10^{\circ} \mathrm{W}-10^{\circ} \mathrm{E}\right)$. Dots on the plots indicate $5 \%$ significance level.

precipitation difference transits from local evaporation in the Sahara sector to moisture convergence in the coast of the Gulf of Guinea clearly demonstrates that the change of surface spectral emissivity in the Sahara and Sahel can affect precipitation in adjacent regions via changes of moisture flux convergence to such regions.

\section{Conclusions}

This study demonstrates that the inclusion of more realistic representation of surface spectral emissivity in the Sahara and Sahel can affect simulated climate in these regions as well as adjacent regions. Over the Sahara and Sahel, the NEW run simulates a warmer surface air temperature and a warmer and wetter planetary boundary layer than the CTL run. The surface energy balance in the NEW run is achieved mainly through an increase of latent heat flux compensated by a reduction of net upward radiative flux. Such conditions favor more convection in the NEW run, leading to more convective precipitation in the Sahara and Sahel. In regions south to the Sahel, particularly the north coastal region of the Gulf of Guinea, the NEW run simulates larger annual-mean precipitation and stronger largescale ascending motion at $500 \mathrm{hPa}$ than the CTL run and such differences are statistically significant. Over West Africa, the rainfall pattern change from the CTL run to the NEW run is caused largely by stronger local evaporation in the Sahara sector, by larger moisture flux convergence in the coastal region of the Gulf of Guinea, and by changes of both local evaporation and moisture convergence in the Sahel.
As far as biases in the CESM with respect to the observations are concerned, the inclusion of surface spectral emissivity in the Sahara and Sahel reduces the cold bias of surface air temperature in the Sahara and the dry biases in the precipitation over the Gulf of Guinea sector. But it also makes the wet bias in precipitation over the Sahel and part of the Sahara worse. Identifying causes of regional biases in a climate model is generally difficult. These biases are usually caused by a myriad of compensating factors in the model. A more realistic representation of surface emissivity in the numerical models fundamentally improves the surface-atmosphere LW coupling and, thus, eliminates one factor that can contribute to such biases. When the biases are worsened in the NEW run, it indicates that the incorrect assumption of surface emissivity in the CTL run has masked the effects of other representations. From this perspective, the direct benefits of inclusion of surface spectral emissivity are twofold: to eliminate one possible cause for the biases and to help reveal biases from other factors.

The GCM biases in both simulated climatology and major modes of Sahel rainfall versus SST variability have been well documented for the CMIP3 models (e.g., Biasutti and Giannini 2006; Cook and Vizy 2006; Joly et al. 2007) and similar biases were seen in the CMIP5 models as well (e.g., Biasutti 2013). Meanwhile, previous studies have noted that the SSTs alone cannot explain the Sahel rainfall variability in the models (Scaife et al. 2009) and local processes such as vegetation changes can affect the Sahel rainfall and its decadal variations (Zeng et al. 1999; Kucharski et al. 2013). Our study shows that another local process, the surface-atmosphere LW coupling through 
spectrally varying surface emissivity, can also affect the Sahel rainfall climatology. A follow-up study would be to investigate, given the multidecadal variations of SST and the projection of future SST changes, to what extent the inclusion of surface spectral emissivity can affect the Sahel rainfall (drought) variations and future change.

Desert emissivity has a strong spectral dependence, which can be as low as $0.6-0.7$ in the IR window band and close to unity in other LW bands. This study indicates that if a GCM does not take such spectral dependence into account, it will have an incorrect band-by-band partition for the surface upward LW flux and its OLR will have an incorrect band-by-band decomposition with excessive flux from the window band. Given that most GCMs do not include proper treatments for surface spectral emissivity, future work would be needed to incorporate such treatments in GCMs, thus making the radiative coupling between the atmosphere and the surface more consistent and more realistic. The CESM, for example, assumes constant graybody emissivity in the surface models (i.e., land, ocean, and sea ice) while assuming blackbody in the atmospheric model. To fully solve such spectral inconsistency across different components in the CESM, the same treatments of surface spectral emissivity in the atmospheric model, as done in this study, should be implemented into the surface models as well. Regional climate models and weather forecast models usually assume blackbody surfaces in their radiation schemes too. Inclusion of surface spectral emissivity should in principle improve the surface-atmosphere LW radiative coupling in all weather and climate models.

Acknowledgments. The authors are thankful to four anonymous reviewers for their insightful and constructive comments. GPCP precipitation data can be obtained from https://www.esrl.noaa.gov/psd/. The ECWMF ERAInterim data are obtained from http://apps.ecmwf.int/ datasets/. The CESM code is obtained from https://svnccsm-release.cgd.ucar.edu/model_versions/cesm1_1_1. This material is based upon work supported by the U.S. Department of Energy, Office of Science, Office of Biological and Environmental Research, Climate and Environmental Science Division under Awards DE-SC0012969 and DE-SC0019278 to the University of Michigan.

\section{REFERENCES}

Adler, R. F., and Coauthors, 2003: The version 2 Global Precipitation Climatology Project (GPCP) monthly precipitation analysis (1979-present). J. Hydrometeor., 4, 1147-1167, https://doi.org/ 10.1175/1525-7541(2003)004<1147:TVGPCP > 2.0.CO;2.

Baldridge, A. M., S. J. Hook, C. I. Grove, and G. Rivera, 2009: The ASTER Spectral Library version 2.0. Remote Sens. Environ., 113, 711-715, https://doi.org/10.1016/j.rse.2008.11.007.
Biasutti, M., 2013: Forced Sahel rainfall trends in the CMIP5 archive. J. Geophys. Res., 118, 1613-1623, https://doi.org/ 10.1002/jgrd.50206.

— late 20th century forcings. Geophys. Res. Lett., 33, L11706, https://doi.org/10.1029/2006GL026067.

Charney, J., W. J. Quirk, S. Chow, and J. Kornfield, 1977: A comparative study of the effects of albedo change on drought in semi-arid regions. J. Atmos. Sci., 34, 1366-1385, https://doi.org/ 10.1175/1520-0469(1977)034<1366:ACSOTE > 2.0.CO;2.

Chen, X., X. Huang, and M. G. Flanner, 2014: Sensitivity of modeled far-IR radiation budgets in polar continents to treatments of snow surface and ice cloud radiative properties. Geophys. Res. Lett., 41, 6530-6537, https://doi.org/10.1002/ 2014GL061216.

Cook, K. H., and E. K. Vizy, 2006: Coupled model simulations of the West African monsoon system: Twentieth- and twentyfirst-century simulations. J. Climate, 19, 3681-3703, https:// doi.org/10.1175/JCLI3814.1.

Dee, D. P., and Coauthors, 2011: The ERA-Interim reanalysis: Configuration and performance of the data assimilation system. Quart. J. Roy. Meteor. Soc., 137, 553-597, https://doi.org/ 10.1002/qj.828.

Druyan, L. M., 2011: Studies of 21st-century precipitation trends over West Africa. Int. J. Climatol., 31, 1415-1424, https:// doi.org/10.1002/joc.2180.

Epule, E. T., C. Peng, L. Lepage, and Z. Chen, 2014: The causes, effects and challenges of Sahelian droughts: A critical review. Reg. Environ. Change, 14, 145-156, https://doi.org/10.1007/ s10113-013-0473-z.

Fontaine, B., M. Gaetani, A. Ullmann, and P. Roucou, 2011: Time evolution of observed July-September sea surface temperature-Sahel climate teleconnection with removed quasi-global effect (1900-2008). J. Geophys. Res., 116, D04105, https://doi.org/10.1029/2010JD014843.

Giannini, A., R. Saravanan, and P. Chang, 2003: Oceanic forcing of Sahel rainfall on interannual to interdecadal time scales. Science, 302, 1027-1030, https://doi.org/10.1126/science.1089357.

Gong, C., and E. Eltahir, 1996: Sources of moisture for rainfall in West Africa. Water Resour. Res., 32, 3115-3121, https:// doi.org/10.1029/96WR01940.

Held, I. M., T. L. Delworth, J. Lu, K. L. Findell, and T. R. Knutson, 2005: Simulation of Sahel drought in the 20th and 21st centuries. Proc. Natl. Acad. Sci. USA, 102, 17 891-17 896, https:// doi.org/10.1073/pnas.0509057102.

Huang, H., Y. Gu, Y. Xue, J. Jiang, and B. Zhao, 2019: Assessing aerosol indirect effect on clouds and regional climate of East/ South Asia and West Africa using NCEP GFS. Climate Dyn., 52, 5759-5774, https://doi.org/10.1007/s00382-018-4476-9.

Huang, X. L., X. H. Chen, D. K. Zhou, and X. Liu, 2016: An observationally based global band-by-band surface emissivity dataset for climate and weather simulations. J. Atmos. Sci., 73, 3541-3555, https://doi.org/10.1175/JAS-D-15-0355.1.

,-- M. Flanner, P. Yang, D. Feldman, and C. Kuo, 2018: Improved representation of surface spectral emissivity in a global climate model and its impact on simulated climate. J. Climate, 31, 3711-3727, https://doi.org/10.1175/JCLI-D-17-0125.1.

Hurrell, J. W., J. J. Hack, D. Shea, J. M. Caron, and J. Rosinski, 2008: A new sea surface temperature and sea ice boundary dataset for the Community Atmosphere Model. J. Climate, 21, 5145-5153, https://doi.org/10.1175/2008JCLI2292.1.

, and Coauthors, 2013: The Community Earth System Model: A framework for collaborative research. Bull. Amer. 
Meteor. Soc., 94, 1339-1360, https://doi.org/10.1175/BAMSD-12-00121.1.

IPCC, 2013: Climate Change 2013: The Physical Science Basis. T. F. Stocker et al., Eds., Cambridge University Press, 1535 pp, https://doi.org/10.1017/CBO9781107415324.

Joly, M., A. Voldoire, H. Douville, P. Terray, and J.-F. Royer, 2007: African monsoon teleconnections with tropical SSTs: Validation and evolution in a set of IPCC4 simulations. Climate Dyn., 29, 1-20, https://doi.org/10.1007/s00382-006-0215-8.

Kato, S., and Coauthors, 2018: Surface irradiances of edition 4.0 Clouds and the Earth's Radiant Energy System (CERES) Energy Balanced and Filled (EBAF) data product. J. Climate, 31, 4501-4527, https://doi.org/10.1175/JCLI-D-17-0523.1.

Kucharski, F., N. Zeng, and E. Kalnay, 2013: A further assessment of vegetation feedback on decadal Sahel rainfall variability. Climate Dyn., 40, 1453-1466, https://doi.org/10.1007/s00382012-1397-x.

Loeb, N. G., and Coauthors, 2018: Clouds and the Earth's Radiant Energy System (CERES) Energy Balanced and Filled (EBAF) top-of-atmosphere (TOA) edition-4.0 data product. J. Climate, 31, 895-918, https://doi.org/10.1175/JCLI-D-170208.1.

Mlawer, E. J., S. J. Taubman, P. D. Brown, M. J. Iacono, and S. A. Clough, 1997: Radiative transfer for inhomogeneous atmospheres: RRTM, a validated correlated-k model for the longwave. J. Geophys. Res., 102, 16 663-16682, https://doi.org/ 10.1029/97JD00237.

Mohino, E., S. Janicot, and J. Bader, 2011: Sahel rainfall and decadal to multi-decadal sea surface temperature variability. Climate Dyn., 37, 419-440, https://doi.org/10.1007/s00382-0100867-2.

Monerie, P. A., E. Sanchez-Gomez, and J. Boé, 2017: On the range of future Sahel precipitation projections and the selection of a subsample of CMIP5 models for impact studies. Climate Dyn., 48, 2751-2770, https://doi.org/10.1007/s00382-016-3236-y.

— T. T. Oudar, and E. Sanchez-Gomez, 2019: Respective impacts of Arctic sea ice decline and increasing greenhouse gases concentration on Sahel precipitation. Climate Dyn., 52, 59475964, https://doi.org/10.1007/s00382-018-4488-5.

Nicholson, S. E., and J. P. Grist, 2003: The seasonal evolution of the atmospheric circulation over West Africa and equatorial Africa. J. Climate, 16, 1013-1030, https://doi.org/10.1175/15200442(2003)016<1013:TSEOTA $>2.0$. CO;2.

Nieto, R., L. Gimeno, and R. M. Trigo, 2006: A Lagrangian identification of major sources of Sahel moisture. Geophys. Res. Lett., 33, L18707, https://doi.org/10.1029/2006GL027232.

Noble, E., L. M. Druyan, and M. Fulakeza, 2014: The sensitivity of WRF daily summertime simulations over West Africa to alternative parameterizations. Part I: African wave circulation. Mon. Wea. Rev., 142, 1588-1608, https://doi.org/10.1175/ MWR-D-13-00194.1.

- — , and —, 2017: The sensitivity of WRF daily summertime simulations over West Africa to alternative parameterizations. Part II: Precipitation. Mon. Wea. Rev., 145, 215-233, https://doi.org/10.1175/MWR-D-15-0294.1.

Rodríguez-Fonseca, B., and Coauthors, 2015: Variability and predictability of West African droughts: A review on the role of sea surface temperature anomalies. J. Climate, 28, 4034-4060, https://doi.org/10.1175/JCLI-D-14-00130.1.

Rotstayn, L. D., and U. Lohmann, 2002: Tropical rainfall trends and the indirect aerosol effect. J. Climate, 15, 2103-2116, https:// doi.org/10.1175/1520-0442(2002)015<2103:TRTATI >2.0.CO;2.

Scaife, A. A., and Coauthors, 2009: The CLIVAR C20C project: Selected twentieth century climate events. Climate Dyn., 33, 603-614, https://doi.org/10.1007/s00382-008-0451-1.

Smith, D. M., N. J. Dunstone, A. A. Scaife, E. K. Fiedler, D. Copsey, and S. C. Hardiman, 2017: Atmospheric response to Arctic and Antarctic sea ice: The importance of oceanatmosphere coupling and the background state. J. Climate, $\mathbf{3 0}$, 4547-4565, https://doi.org/10.1175/JCLI-D-16-0564.1.

Sud, Y. C., and M. Fennessy, 1982: A study of the influence of surface albedo on July circulation in semi-arid regions using the GLAS GCM. J. Climatol., 2, 105-125, https://doi.org/ 10.1002/joc.3370020202.

Sylla, M. B., P. M. Nikiema, P. Gibba, I. Kebe, and N. A. B. Klutse, 2016: Climate change over West Africa: Recent trends and future projections. Adaptation to Climate Change and Variability in Rural West Africa, J. Yaro and J. Hesselberg, Eds., Springer, 25-40.

Taylor, C. M., E. F. Lambin, N. Stephenne, R. J. Harding, and R. L. H. Essery, 2002: The influence of land use change on climate in the Sahel. J. Climate, 15, 3615-3629, https://doi.org/ 10.1175/1520-0442(2002)015<3615:TIOLUC >2.0.CO;2.

Thorncroft, C., H. Nguyen, C. Zhang, and P. Peyrillé, 2011: Annual cycle of the West African monsoon: Regional circulations and associated water vapour transport. Quart. J. Roy. Meteor. Soc., 137, 129-147, https://doi.org/10.1002/qj.728.

Wilber, A. C., D. P. Kratz, and S. K. Gupta, 1999: Surface emissivity maps for use in satellite retrievals of longwave radiation. NASA Tech. Publ. NASA/TP-1999-209362, 35 pp., http:// www-cave.larc.nasa.gov/pdfs/Wilber.NASATchNote99.pdf.

Xue, Y., and J. Shukla, 1993: The influence of land surface properties on Sahel climate. Part 1: Desertification. J. Climate, 6 2232-2245, https://doi.org/10.1175/1520-0442(1993)006<2232: TIOLSP $>2.0 . \mathrm{CO} ; 2$.

— , and Coauthors, 2010: Intercomparison and analyses of the climatology of the West African Monsoon in the West African Monsoon Modeling and Evaluation project (WAMME) first model intercomparison experiment. Climate Dyn., 35, 3-27, https://doi.org/10.1007/s00382-010-0778-2.

_ ability and surface-related forcings: Second West African Monsoon Modeling and Evaluation Project Experiment (WAMME II). Climate Dyn., 47, 3517-3545, https://doi.org/ 10.1007/s00382-016-3224-2.

Zeng, N., J. D. Neelin, K.-M. Lau, and C. J. Tucker, 1999: Enhancement of interdecadal climate variability in the Sahel by vegetation interaction. Science, 286, 1537-1540, https:// doi.org/10.1126/science.286.5444.1537.

Zhou, D. K., A. M. Larar, X. Liu, W. L. Smith, L. L. Strow, P. Yang, P. Schlüssel, and X. Calbet, 2011: Global land surface emissivity retrieved from satellite ultraspectral IR measurements. IEEE Trans. Geosci. Remote Sens., 49, 1277-1290, https:// doi.org/10.1109/TGRS.2010.2051036. 
